\title{
A planície costeira holocênica de Campos Verdes (Laguna, SC): evolução sedimentar inferida a partir de georradar (GPR), granulometria e minerais pesados
}

\author{
Ana Paula Burgoa Tanaka ${ }^{1}$, Paulo César Fonseca Giannini², Milene Fornari', Daniel \\ Rodrigues do Nascimento Junior', André Oliveira Sawakuchi', Selma Isabel Rodrigues, \\ Priscila Melo Leal Menezes ${ }^{1,3}$, Paulo DeBlasis ${ }^{5}$ \& Jorge Luiz Porsani ${ }^{4}$
}

\begin{abstract}
Resumo Situada no litoral sul de Santa Catarina, a planície de Campos Verdes caracteriza-se por feixes de cordões litorâneos, transversais à costa atual, separados entre si por truncamentos em padrão côncavo-convexo. Parte dos cordões superpõe-se por campos de paleodunas parabólicas orientadas para SW, atribuídos à geração eólica 3 (pós-máxima inundação holocênica). Limita-se a SW por uma faixa arenosa $1 \mathrm{~m}$ mais alta, sem cordões aparentes, sobre a qual se assentam quatro sambaquis. A evolução da planície teve início a partir do ancoramento dos primeiros cordões sobre esta faixa, que corresponderia a um paleopontal formado segundo os modelos de circulação lagunar de Zenkovitch e que teria servido como "armadilha" para o acúmulo sedimentar. Esta hipótese é reforçada pelo mergulho para norte de refletores GPR, indicação de progradação nesse rumo. O padrão McLaren de variação granulométrica "mais fino, melhor selecionado e mais negativo" para norte pode ser atribuído a sucessivo retrabalhamento sedimentar no decorrer da progradação. Em perfil longitudinal aos cordões, a tendência de engrossamento, melhora de seleção e assimetria mais positiva para $\mathrm{W}$ refletiria $\mathrm{o}$ transporte por deriva litorânea. A variação de minerais pesados evidencia maior concentração de componentes instáveis, em detrimento dos ultraestáveis, nas porções norte e oeste da planície, com aumento da relação turmalina/zircão para NW. A queda de maturidade mineralógica no setor formado ao final da progradação pode ser atribuída a: 1. concentração gradual por seleção hidraúlica; 2 . aumento de aporte sedimentar da frente deltaica do rio Tubarão; e 3. menor tempo de atuação da dissolução pós-deposicional nos cordões mais novos.
\end{abstract}

Palavras-chave: sedimentologia, progradação, cordões litorâneos, dunas eólicas, GPR.

Abstract The holocene coastal plain of Campos Verdes (Laguna, state of Santa Catarina, southern Brazil): sedimentary evolution based in ground penetrating radar, grain-size and heavy minerals. Campos Verdes region, in Laguna, mid-south coast of Santa Catarina, is characterized by sets of beach ridges alignments, oriented transversal to the present coastline and separated from each other by truncations with a concave-convex pattern. This strandplain is limited towards SW by a higher area $(1 \mathrm{~m})$ without beach ridges, where four shell mounds are located. The alignments are superposed by several groups of inactive parabolic dunes, attributed to the aeolian generation 3 (post maximum Holocene flooding). The sedimentary growing began in the southwest (higher area), where the former beach ridges developed anchored on a sandy spit. This spit was formed according to the Zenkovitch's models of lagoonal circulation; moreover, it would have worked as a "trap" for the accumulation of sediments that formed the strandplain. This hypothesis is highlighted by the GPR sections, with reflectors dipping towards $\mathrm{N}$, indication of progradation towards this azimuth. The McLaren's granulometric variation pattern of "fining, better sorting and more negative skewness" towards $\mathrm{N}$ can be interpreted as resulting from a progressive sedimentary reworking during progradation. In a longitudinal profile, the pattern of "coarsening, better sorting and more positive skewness" towards W, suggests transport by longshore currents towards this azimuth. The variation in the heavy minerals assemblage shows a higher concentration of unstable components in opposite to the decrease of ultrastable components towards $\mathrm{N}$ and $\mathrm{W}$, with an increase in the relation tourmaline/zircon towards NW. This decreasing mineralogical maturity towards the sector formed in the end of the progradation can be attributed to three factors: 1 . progressive concentration by hydraulic sorting; 2 . increase in the sedimentary input of newer sediments, because of the stronger influence of Tubarão river deltaic front; and 3. least time for the action of pos-depositional solution in the newer beach ridges.

Keywords: sedimentology, progradation, beach ridges, eolian dunes, GPR.

1 - Universidade de São Paulo, Instituto de Geociências, Programa de Pós-Graduação em Geoquímica e Geotectônica, São Paulo (SP), Brasil.E-mails: ana.tanaka@usp.br, milenefornari@yahoo.com.br, danieljr@usp.br

2 - Universidade de São Paulo, Instituto de Geociências, Departamento de Geologia Sedimentar e Ambiental, São Paulo (SP), Brasil. Emails: pcgianni@usp.br, andreos@usp.br

3 - IPT - Instituto de Pesquisas Tecnológicas do Estado de São Paulo, São Paulo (SP), Brasil. E-mail: prileal@ipt.br

4 - Universidade de São Paulo, Instituto de Astronomia e Geofísica, São Paulo (SP), Brasil. E-mails: selma@iag.usp.br, porsani@iag.usp.br

5 - Universidade de São Paulo, Museu de Arqueologia e Etnologia, São Paulo (SP), Brasil. E-mail: deblasis@usp.br 
INTRODUÇÃO A partir do Holoceno médio e durante o Holoceno tardio, extensas planícies costeiras com cordões litorâneos formaram-se ao redor do globo. No hemisfério sul, o desenvolvimento de planícies de cordões foi favorecido pela queda do nível relativo do mar (NRM), após seu máximo holocênico (Isla 1989), e tem sido objeto de estudos sedimentológicos e/ou estratigráficos em diferentes setores costeiros da Austrália (Roy et al. 1994, Bristow et al. 2006, Brooke et al. 2008), Nova Zelândia (Woodroffe et al. 1983), África austral (Blivi et al. 2002) e Argentina (Isla \& Bujalesky 2000). No Brasil, destacam-se, entre outras regiões estudadas, a foz do rio São Francisco, SE/BA (Dominguez et al. 1983), a foz do rio Paraíba do Sul, RJ (Dias \& Kjerfve 2009), a Ilha Comprida, SP (Giannini et al. 2003, 2009, Sawakuchi et al. 2008, Guedes 2009), as planícies adjacentes à baía de Paranaguá e a Ilha do Mel, PR (Angulo et al. 1996, Lessa et al. 2000, Angulo et al. 2009), a região de Tijucas e Navegantes, SC (Fitzgerald et al. 2007), a enseada da Pinheira, SC (Hesp et al. 2009) e a planície litorânea do Rio Grande do Sul a norte de Tramandaí (Tomazelli \& Villwock 2005, Dillenburg et al. 2009). Nestas regiões, o registro de progradação mais ou menos continuada deve-se à manutenção de taxa de aporte sedimentar superior à de geração de espaço de acomodação por aumento de NRM. O desenvolvimento destas planícies teria começado assim durante a desaceleração da taxa de subida de NRM, pouco antes do nível máximo, alcançado por volta de 5000 anos AP (Suguio et al. 1985, Martin et al. 1988, Angulo et al. 2006).

Campos Verdes é uma das principais planícies com expressão de feixes de cordões litorâneos no trecho do litoral sul catarinense entre Jaguaruna e Imbituba. Apresenta, além disso, uma série de particularidades: o padrão côncavo-convexo de truncamento de alinhamentos de cordões (Giannini 1993, Tanaka et al. 2008); a posição retrobarreira, entre desembocaduras lagunares, o que a torna exemplo de evolução sedimentar em área de equilíbrio erosivo-deposicional instável; a orientação dos cordões, dominantemente transversal à linha de costa de mar aberto, o que suscita dúvidas sobre o rumo de crescimento progradacional; o contraste entre seu caráter regressivo e o cenário regional dominante, caracterizado por campos de dunas livres sobre estreitas planícies e barreiras transgressivas, com linha de costa quase estável durante a segunda metade do Holoceno; e a alternância entre cordões litorâneos e campos de dunas livres (Giannini 1993), o que sugere intercalação no tempo entre pulsos de evolução progradacional e episódios de deposição eólica (Tanaka et al. 2008, Giannini 2007). Apresenta, sob este último aspecto, padrão similar ao encontrado na planície da Pinheira, SC, na Ilha Comprida, SP, e junto à foz do rio São Francisco, SE/AL (Giannini 2007, Sawakuchi et al. 2008, Hesp et al. 2009), o qual pode ser considerado chave para a compreensão das relações entre migração da linha de costa e iniciação e crescimento de campos de dunas eólicas. No âmbito arqueológico, a planície destaca-se por situar-se em meio a uma das mais sig- nificativas áreas de registro da cultura sambaquieira no país, tanto em termos de quantidade como de dimensões dos sítios (Giannini et al. 2005, DeBlasis et al. 2007).

Dentro deste contexto, o objetivo principal deste artigo é verificar o rumo de crescimento progradacional e reconstituir a evolução sedimentar da planície costeira de Campos Verdes, de modo a relacionar os padrões de variação granulométrica e índices de minerais pesados com os possíveis controles exercidos pela dinâmica sedimentar durante a regressão. O tema pode ser considerado chave para compreender melhor as relações entre mudanças da linha de costa, desenvolvimento de dunas eólicas e ocupação da população sambaquieira neste setor do litoral brasileiro. A análise dos padrões de variação de atributos sedimentológicos no decorrer de processos progradacionais é assunto ainda pouco explorado na investigação deste litoral. Estudos que relacionam a variação de índices de minerais pesados baseados em Morton \& Hallsworth $(1994,1999)$ com mudanças na dinâmica costeira em escala de tempo milenar são escassos na literatura mundial e inéditos no litoral catarinense, o que reforça o interesse deste trabalho.

ÁREA DE ESTUDO A planície de Campos Verdes situa-se no município de Laguna, litoral sul de Santa Catarina, em posição geográfica intermediária a duas desembocaduras lagunares, a do Camacho, a SW, e a de Entrada da Barra, a NE (Fig. 1). Encontra-se imediatamente ao interior da barreira costeira holocênica que separa o mar aberto da laguna na região, apresentando, portanto, posição retrobarreira (backbarrier). Esta planície integra uma das várias feições sedimentares que subdividem o sistema lagunar centro-sul catarinense entre Jaguaruna e Imbituba em corpos de água semicirculares (Giannini 1993, 2002) e que numa primeira aproximação podem ser relacionados ao padrão de estabilidade de circulação lagunar modelado por Zenkovitch (1971). Separa, desse modo, a laguna Santa Marta, a SW, da laguna Santo Antônio, a NE. Na margem sul da laguna Santo Antônio, situam-se ainda as desembocaduras dos principais distributários ativos do delta lagunar do rio Tubarão.

Geomorfologicamente, as características mais marcantes da planície de Campos Verdes são: 1. feixes de cordões litorâneos, separados entre si por truncamentos dispostos em padrão côncavo-convexo em planta; 2 . conjuntos de dunas parabólicas inativas orientadas de NE para SW, superpostas aos alinhamentos de cordões; e 3. uma faixa arenosa sem expressão de cordões litorâneos, cerca de $1 \mathrm{~m}$ mais alta, orientada segundo SE-NW e situada no limite sudoeste da planície. Sobre esta faixa se encontram os quatro sambaquis de Carniça (Hurt 1974), um deles (Carniça I) incluído entre os maiores do litoral sul catarinense, região que exibe grande densidade destes sítios arqueológicos (DeBlasis et al. 2007). Esse cenário é um recorte muito representativo do mosaico de processos e produtos sedimentares e antrópicos interdependentes que caracteriza os sistemas deposicionais do Holoceno nesse litoral.

A planície retrobarreira de Campos Verdes faz 


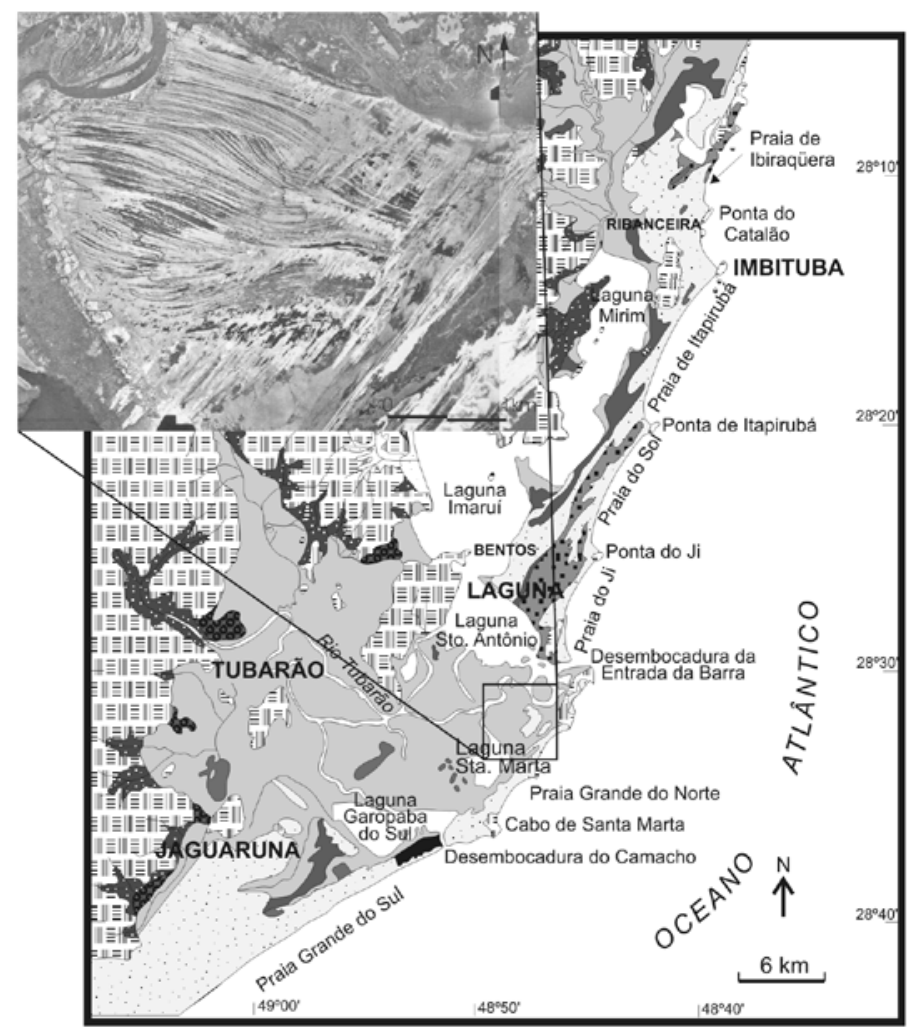

\section{SISTEMAS DEPOSICIONAIS COSTEIROS} QUATERNÁRIOS

\section{Sistema Planície Costeira}

$E$ Holocênico

Pleistocênico

Sistema Barreira

Holocênico

Sistema Lagunar

Holocênico

Sistema Eólico

$\because \therefore$ Indiferenciado

\section{OUTRAS UNIDADES}

Sedimentos continentais indiferenciados Quaternário

Sedimentos continentais indiferenciados Terciário

E-IiIi Rochas igneas, metamórficas e sedimentares Pré-Cenozóico

Figura 1 - Localização da planicie retrobarreira de Campos Verdes e integração com os sistemas deposicionais entre Jaguaruna e Imbituba (SC). Mapa-base simplificado de Giannini (1993) por Giannini \& Santos (1994). Fotografia aérea vertical de Cruzeiro do Sul Serviços Aéreos, vôo de 1952-1956. Planície costeira ou de cordões corresponde ao strandplain de Hesp et al. (2009).

parte de cenário regional (Fig. 1) caracterizado pela justaposição de quatro tipos de sistemas deposicionais costeiros: o lagunar, o barreira, o planície de cordões (strandplain) e o eólico (Giannini 1993, 2002; Giannini et al. 2007). Alternativamente, Hesp et al. (2009) caracterizam a cobertura sedimentar quaternária da região como formada por planícies de cordões (strandplains) e barreiras holocênicas, estas abrangendo lagunas e depósitos eólicos (dunas frontais e campos de dunas transgressivos). No entanto, as lagunas da região desenvolvem-se tanto à retaguarda de barreiras de origem transgressiva como a partir do afogamento de vales incisos sobre a planície costeira pleistocênica, não sendo portanto feições exclusivamente associadas nem a um nem a outro, o que justifica atribuir-lhe status de sistema deposicional independente. $\mathrm{O}$ mesmo se aplica ao sistema eólico. A planície de Campos Verdes insere-se neste contexto regional como feição de interface entre laguna e barreira, com recobrimento parcial por campos de dunas eólicas.

MÉTODOS 34 amostras (Fig. 2) foram coletadas sub-superficialmente, em 18 pontos, com controle faciológico e/ou estratigráfico, em trincheiras de 0,5 a 2 $\mathrm{m}$ de profundidade, abertas manualmente em depósitos sedimentares naturais. A coleta foi pontual, em quantidade suficiente para perfazer uma massa de aproximadamente $1 \mathrm{~kg}$ por amostra.

As seções geofísicas foram levantadas em caminhamento segundo a configuração em $\mathrm{U}$, fechado para NW da estrada de Campos Verdes (Fig. 3), utilizando-se de Georradar ou Radar de Penetração de Solo (Ground Penetrating Radar - GPR). O GPR é um método geofísico de alta resolução que emprega a propagação e reflexão de ondas eletromagnéticas para estudar a subsuperfície da Terra. A antena transmissora radia pulsos eletromagnéticos em direção a subsuperfície e a antena receptora registra os sinais refletidos na interface entre os alvos que apresentam propriedades eletromagnéticas contrastantes (permissividade dielétrica, condutividade elétrica e permeabilidade magnética). Os princípios físicos e matemáticos envolvidos na propagação de ondas eletromagnéticas estão fundamentados nas equações de Maxwell (Reitz et al. 1982). Informações detalhadas sobre o método e os procedimentos envolvidos podem ser encontradas na literatura (Davis \& Annan 1989, Daniels 1996, Porsani 1999).

As amostras coletadas foram submetidas à análise granulométrica por peneiramento convencional, em intervalos de 0,5 phi na escala de WentworthKrumbein. O tratamento dos resultados brutos de distribuição em massa incluiu contabilização do percentual de cada classe granulométrica e cálculo de estatisticas (diâmetro médio, desvio padrão e assimetria) pelo método analítico dos momentos de Pearson. Os resultados assim obtidos foram lançados em gráficos em função da distância (transversal e longitudinal aos feixes de cordões litorâneos), com o intuito de verificar possíveis padrões ou tendências de variação espacial e desse 


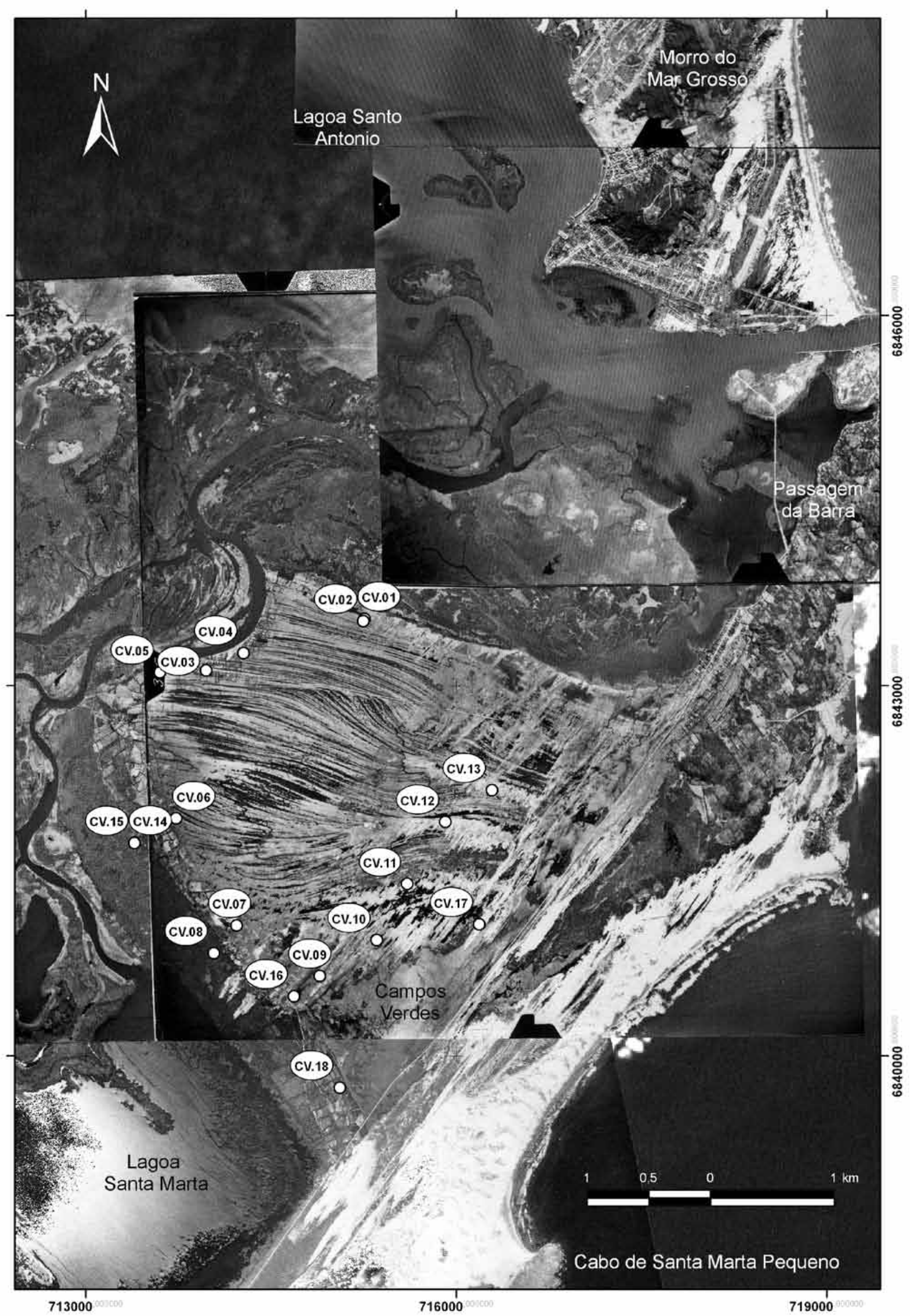

Figura 2 - Distribuição dos pontos de amostragem na planicie de Campos Verdes. Mosaico de fotografias aéreas verticais de Cruzeiro do Sul Serviços Aéreos, vôo de 1952-1956. 


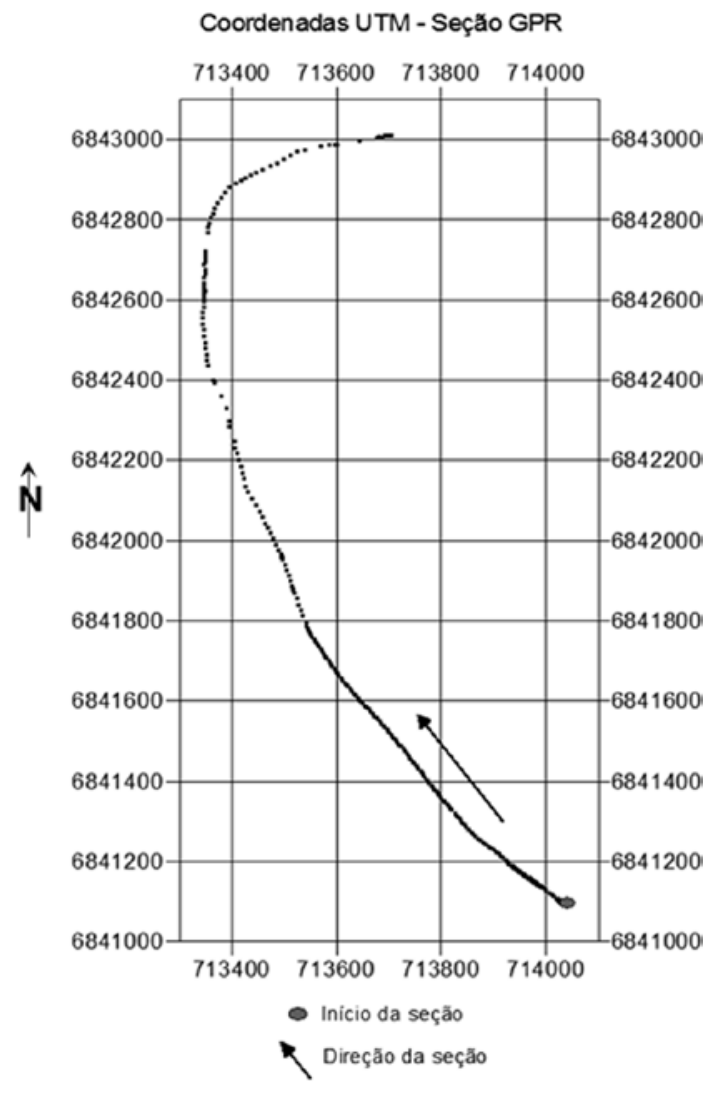

Figura 3 - Localização e configuração do perfil de caminhamento para obtenção de seção geofisica por GPR.

modo interpretar o rumo de crescimento progradacional e a paleoderiva litorânea da planície. Foram estudadas desse modo tanto amostras de cordões (em perfis transversal e longitudinal) quanto de dunas eólicas (em perfil transversal).

A separação densimétrica da fração areia muito fina foi realizada pelo método de afundamento em bromofórmio, $\operatorname{CHBr}_{3}\left(\rho=2,85 \mathrm{~g} / \mathrm{cm}^{3}\right)$. Após seca, a fração de minerais pesados foi submetida à separação magnética com imã portátil. Lâminas permanentes foram montadas a partir da imersão dos grãos da fração pesada nãomagnética em bálsamo do Canadá. A quantificação de minerais pesados ao microscópio petrográfico seguiu o método de contagem, em linhas aleatórias (ribbon counting: Galehouse 1971, Mange and Maurer 1992), de pelo menos 100 grãos transparentes não micáceos. Para a obtenção dos índices turmalina-zircão (iTZ $=100 *$ turmalina / turmalina+zircão), hornblenda-turmalina (iHT= $100 *$ hornblenda / hornblenda+turmalina) e rutilo-zircão (iRZ $=100 *$ rutilo / rutilo+zircão) contaram-se 200 grãos dos dois minerais envolvidos em cada índice, conforme proposto por Morton \& Hallsworth (1994, 1999). O índice somatório de minerais pesados ultraestáveis $(\mathrm{iZTR}=$ zircão + turmalina + rutilo) foi obtido de acordo com a definição de Hubert (1962). Calcularam-se de modo análogo os índices de metaestáveis (iMET $=$ epídoto + estaurolita + sillimanita + cianita + granada + monazi- ta) e de instáveis (iINS $=$ hornblenda + hiperstênio + augita + dipsídio + tremolita). Lançaram-se estes três índices de maturidade, mais o iTZ, iHT e iRZ, em gráficos de freqüência versus distância, em perfis transversal (para amostras de cordão e de duna eólica) e longitudinal (para amostras de cordão) ao feixe de alinhamentos, bem como em mapas de interpolação.

As retas de regressão e os valores de coeficiente de determinação $\left(\mathrm{r}^{2}\right)$ obtiveram-se por meio do software Microsoft ${ }^{\circledR}$ Excel. O critério estatístico utilizado para avaliar os resultados de $\mathrm{r}$ foi o nível de significância $(\alpha)$ ou erro I, para a rejeição de hipótese nula (aceitação da correlação), de acordo com o teste unicaudal t de Student. Este nível mede a probabilidade de a correlação indicada ser inexistente. Para o teste, admitiram-se resultados de correlação linear com nível $\alpha$ menor ou igual a 0,4. Para inferir o rumo de transporte através do software GSTAST (Grain Size Trend Analysis with Significant Test), desenvolvido por Chang et al. (2001), assumiram-se valores de 0,05 para o nível de significância, $1500 \mathrm{~m}$ para distância crítica e 100 para número de iterações. O programa utiliza os padrões indicadores de transporte sedimentar de McLaren \& Bowles (1985) combinados com o conceito de rede de transportes de Gao \& Collins (1992), onde cada ponto amostrado é comparado individualmente a todos os seus vizinhos, dentro de uma distância característica, escolhida pelo usuário. Os mapas de interpolação foram obtidos com o software ESRI ${ }^{\circledR}$ ArcMap $^{T M} 9.3$.

\section{APRESENTAÇÃO E DISCUSSÃO DE RESULTADOS Feições morfológicas \\ CORDÕES E INTERCORDÕES Através da identifi-} cação, em fotografias aéreas, de truncamentos de alinhamentos, foram delimitados dez feixes de cordões litorâneos, numerados em ordem crescente de sul para norte (Fig. 4). Os feixes apresentam forma em planta ora lenticular, tanto côncavo-convexa $(1,5$ e 8$)$ como côncavo-côncava ( 2 e 4), ora curvilínea com limites subparalelos entre si (3, 6, 7, 9 e 10). Internamente aos feixes, a forma curvilínea dos cordões comparece em todos eles. Os feixes 9 e 10, apesar de bastante encobertos pelos depósitos eólicos, aparentam ser constituídos por alinhamentos mais retilíneos que os demais. $\mathrm{O}$ truncamento entre os feixes 6,7 e 8 é tênue, sendo que o feixe 7 apresenta menor largura e só pôde ser bem delimitado com base na geometria de sua parte oeste. Os feixes 2, 3, 4 e 5 apresentam larguras semelhantes e acunhamento a leste, onde se encontram encobertos por dunas eólicas. Este conjunto compõe um padrão geométrico hummocky (em planta) com o conjunto de feixes 6,7 e 8 . Os feixes 1 e 2 são bastante curvilíneos e com orientação acentuadamente distinta dos demais. Enquanto a orientação dominante dos feixes 3 a 10 varia entre NW e E-W, os feixes 1 e 2 apresentam-se orientados preferencialmente segundo NE.

Os cordões litorâneos da planície retrobarreira de Campos Verdes (Fig. 5A) atendem à definição abrangente dada a este termo por Otvos (2000): "formas reliquiares, semi-paralelas, em alinhamentos 


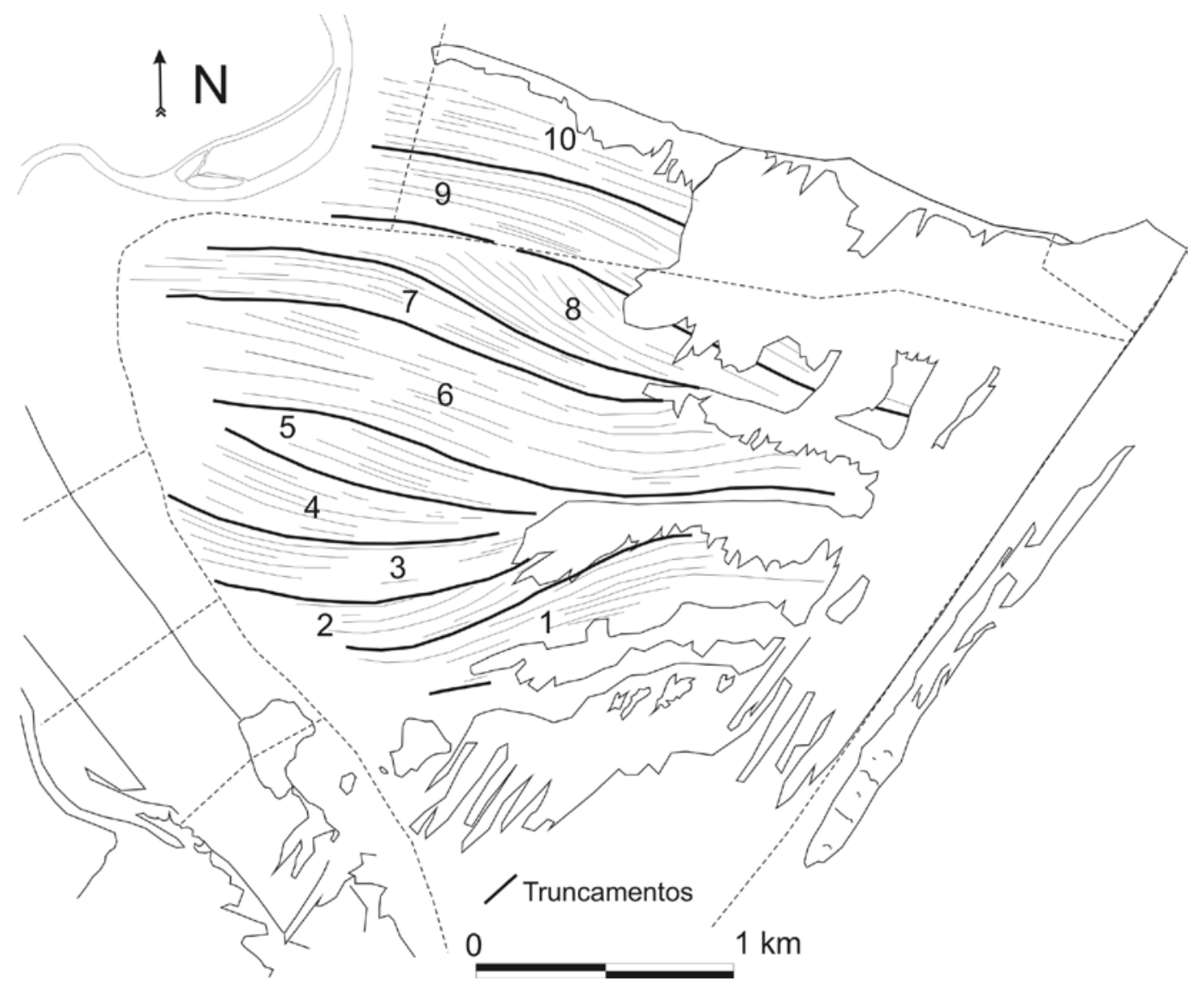

Figura 4 - Feixes de alinhamentos de cordões, delimitados por truncamentos delineados em fotointerpretação. Numeração crescente de sul para norte. A porção sem cordões aparentes na parte leste da área corresponde à cobertura por depósitos eólicos.

múltiplos, que podem ser originadas tanto por ondas, como pelos ventos". Atendem também à definição mais específica de beach ridge formulada por Hesp (1984, 1999) e Hesp et al. (2005), que restringe o termo às formas geradas por ondas (em contraposição aos foredune ridges), e inclui entre elas aquelas "relacionadas à variação do nível médio das águas de lagunas e estuários" (Hesp et al. 2005), ainda que esta variação não seja imprescindível para explicar sua gênese. A origem subaquosa dos cordões de Campos Verdes foi admitida em vista de ausência, nos dados de GPR e de campo, de qualquer indício de deposição eólica na forma de dunas frontais. Refletores inclinados observados abaixo de $1 \mathrm{~m}$ na seção geofísica (GPR) transversal aos feixes (item GPR, Fig. 8A) refletem o mergulho das paleossuperfícies deposicionais, independentemente da fácies ali representada e, portanto, da origem eólica (duna frontal) ou subaquosa do depósito. Nas trincheiras e exposições, as estruturas sedimentares são raramente preservadas, mas, quando identificadas, correspondem a estratificações plano-paralelas incipientes, que podem ser atribuídas a espraiamento de ondas. Com base nestes dados, as cristas identificadas em foto aérea e no campo foram admitidas como fácies morfológica de cordão litorâneo sensu Hesp et al. (2005) e as depressões como fácies de intercordão.
Em campo, a diferença entre as cristas (cordões sensu stricto) e as depressões (intercordões) é tênue (Fig. 5B), dada por desnível topográfico suave, decimétrico. Esta diferença pode, todavia tornar-se nítida, especialmente nas áreas menos modificadas pelo homem (Fig. 5C), graças a contrastes entre vegetação de porte maior, arbustiva a arbórea, nas cristas, e vegetação dominada por gramíneas, nas depressões mais freqüente ou intensamente alagadas (Fig. 5D).

Os cordões da planície de Campos Verdes possuem de 4 a $10 \mathrm{~m}$ de largura de calha e estendem-se por quilômetros até serem encobertos a leste por depósitos eólicos (Fig. 4 e 6). A orientação dos alinhamentos é transversal a atual linha de costa, sendo que a mudança brusca de orientação gera os truncamentos (Fig. 4), indicativos de erosão seguida de retomada da deposição. Bristow \& Pucillo (2006) relacionam a erosão expressa em truncamentos entre feixes de cordão a episódios de tempestade ou mudança na direção dos paleoventos responsáveis pela geração de ondas.

A SW da planície de cordões encontra-se uma faixa NW-SE topograficamente elevada e sem cordões aparentes, que pode ter servido de âncora para o início do crescimento dos cordões de Campos Verdes (Giannini 1993, Tanaka et al. 2008). Esta hipótese, a ser melhor verificada com dados de GPR e sedimentologia, ajuda 

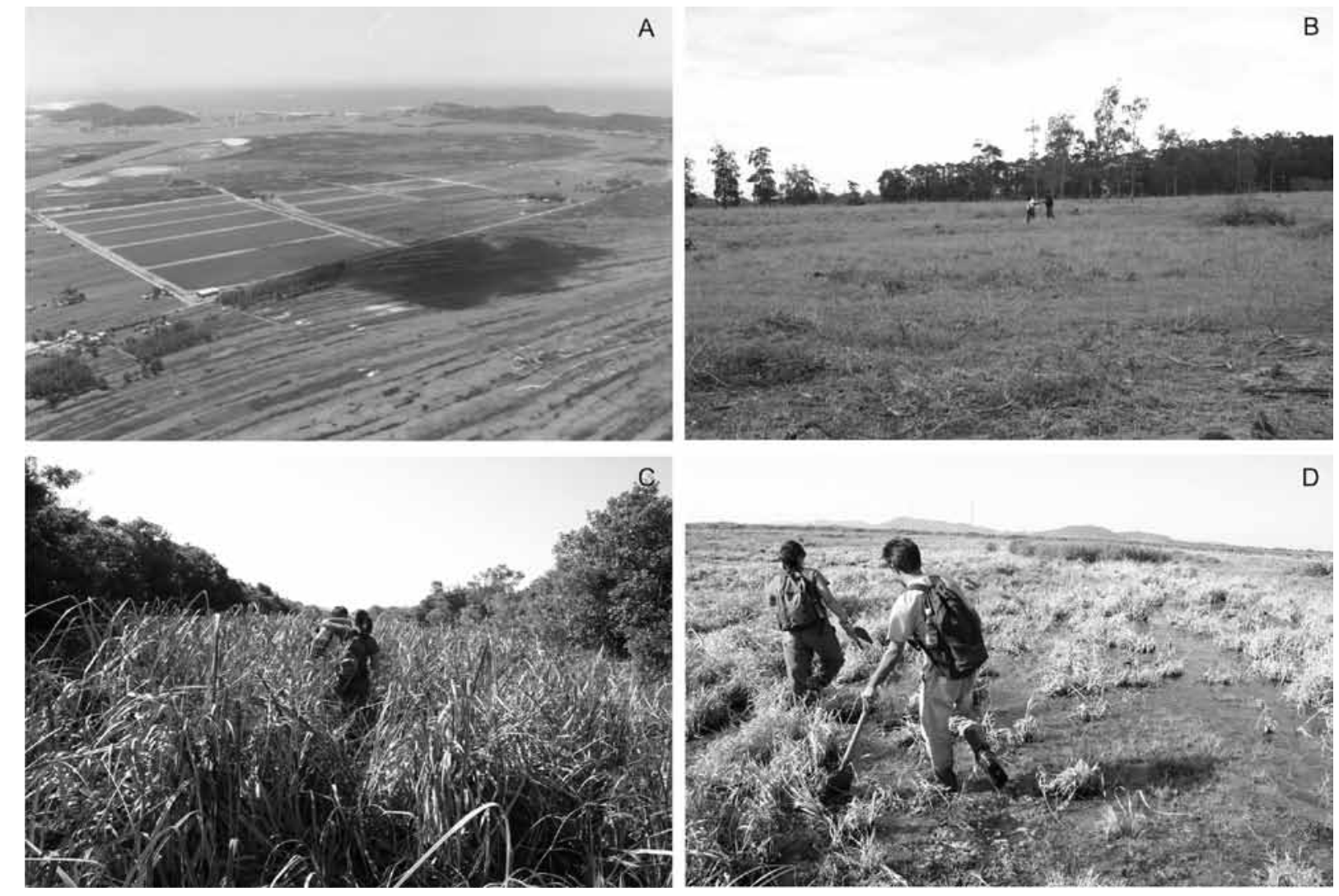

Figura 5 - Aspectos de campo dos cordões litorâneos de Campos Verdes. A) Vista aérea oblíqua da porção sudoeste da planície de cordões (primeiro plano) e da desembocadura do rio Tubarão, com os morros de Laguna e Passagem da Barra, ao fundo (Foto Bacha, Laguna, 2001). B) Cordões paralelos com gradiente topográfico decimétrico entre crista e depressão, cobertos por vegetação rasteira, em porção desmatada da planície, próximo ao ponto CV.06. C) Vegetação dominada por gramínea (Scirpus maritimus L.), em depressão intercordões (centro da foto), em contraste à vegetação arbórea, nas cristas, próximo ao ponto CV.11. D) Depressão intercordões alagada, entre os pontos CV.11 e CV.12.

a explicar o fato de a orientação geral ou dominante dos alinhamentos ser discordante do eixo maior da barreira (SW-NE).

PALEODUNAS EÓLICAS Em fotografias aéreas verticais, é possível observar que pelo menos quatro conjuntos de dunas parabólicas inativas (provavelmente antigos campos de dunas), orientadas de NE para SW, superpõem-se aos alinhamentos de cordões (Fig. 6). Cada um desses conjuntos de dunas estende-se ao longo de um mesmo cordão por mais de $1 \mathrm{~km}$. Não foram encontrados em campo vestígios do conjunto de dunas delimitado por aerofotointerpretação na parte norte da planície (próximo ao feixe de cordões 1 na Fig. 4). A sua não preservação pode ser atribuída à intensa ocupação da planície pelo homem nesse setor (centro da antiga Vila de Carniça, hoje Campos Verdes). As frentes de lobos deposicionais (Fig. 6A) de geometria parabólica são, em alguns casos, delimitadas em sua porção convexa por terrenos alagados.

Próximo ao sambaqui Carniça I, na porção sudoeste da planície, encontram-se dunas eólicas maiores que aproximadamente $5 \mathrm{~m}$ de altura (Fig. 6B) que apresentam geometria parabólica e avançam sobre os depósitos da margem lagunar de Santa Marta. As dunas localizadas na parte leste da planície, mais próximas à Estrada Geral ou do Telégrafo (estrada retilínea SW-NE na Fig. 6) podem ser diferenciadas das demais por suas grandes alturas máximas, maiores que $10 \mathrm{~m}$ (Fig. 6C e 6D).

Dentre as quatro gerações de dunas eólicas quaternárias reconhecidas na região de Jaguaruna-LagunaImbituba (Giannini 1993, 2002, 2007, Giannini et al. 2001, 2005, 2007), os depósitos eólicos de Campos Verdes possuem características mais compatíveis com a geração eólica 3: são formas fixas, constituídas por areias incoesas de cor esbranquiçada, com sinais extensivos de incipiente pedogênese e colonização vegetal (Giannini 1993). No modelo evolutivo proposto por Giannini (1993) e Giannini et al. (2007), as gerações eólicas 1 e 2 foram correlacionadas aos máximos transgressivos do Pleistoceno superior e do Holoceno, respectivamente, enquanto a gerações 3 e 4 seriam posteriores à máxima inundação do Holoceno, sendo a geração 3 inativa e a 4 ativa. Dentro desse modelo, a atribuição das dunas eólicas de Campos Verdes à geração 3 é coerente com o fato de a planície de cordões sobre a qual estas dunas ocorrem ter-se desenvolvido por progradação, portanto após a formação da barreira no máximo transgressivo. 

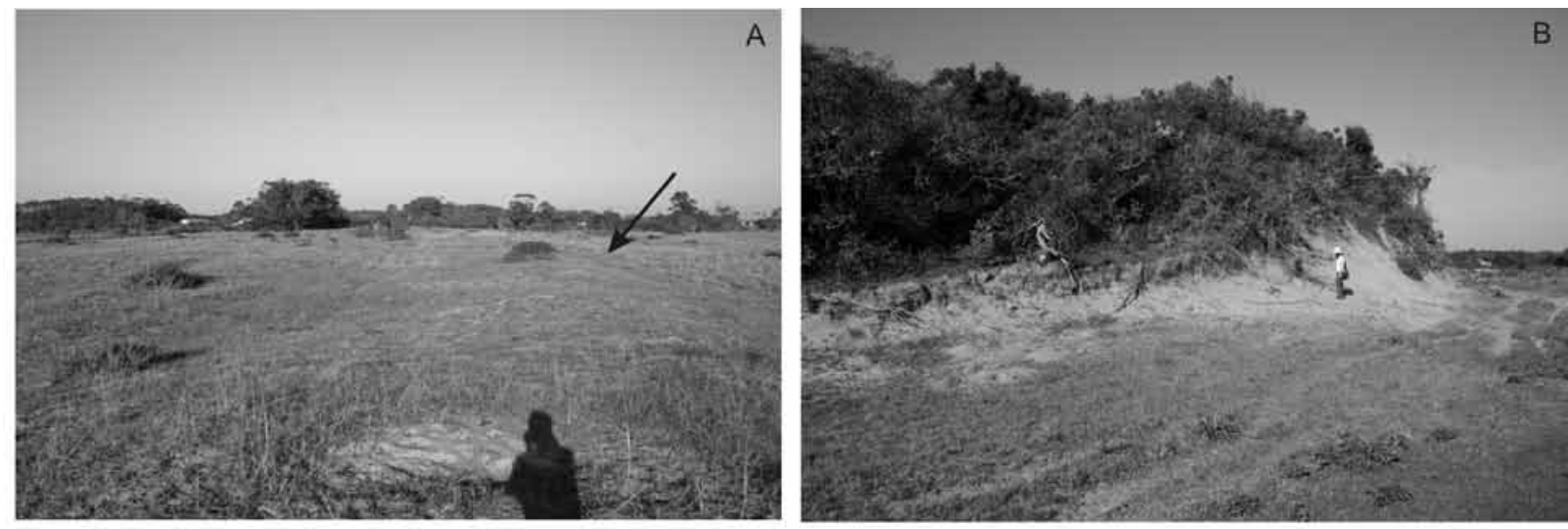

C
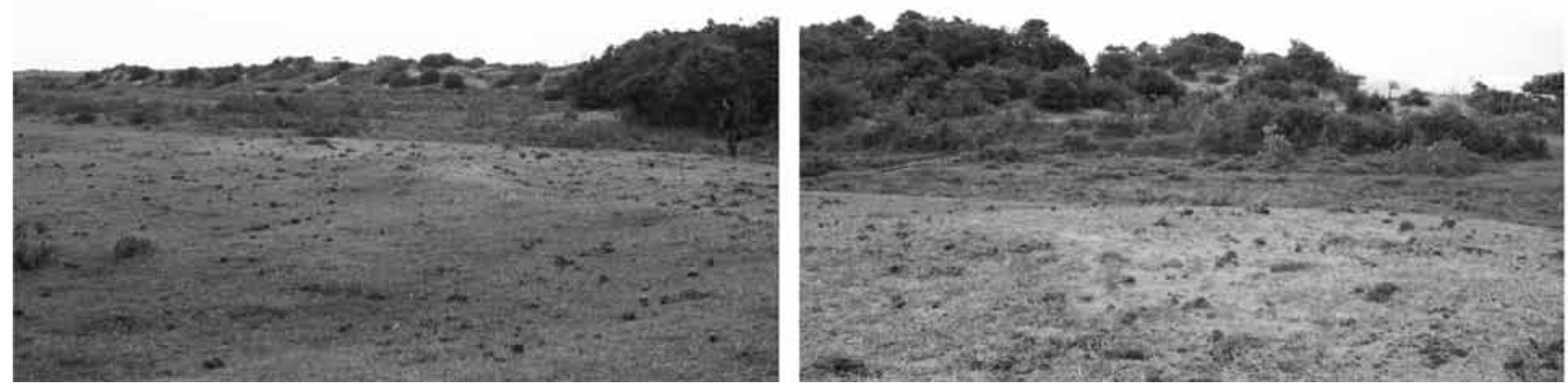

Figura 6 - Aspecto das paleodunas parabólicas de Campos Verdes. A) Frente de lobo deposicional na região do ponto CV.09.B) Depósitos eólicos no ponto CV.08, proximidades do sambaqui Carniça I. O corte principal (mais alto) é aproximadamente perpendicular ao paleovento efetivo na formação do depósito. C) Campo de dunas na parte leste da planície no ponto CV.17, próximo à Estrada Geral, em vista lateral, a partir de SE. D) Detalhe do cordão de precipitação externo (sudeste) do campo de dunas da fotografia anterior.

MARGEM LAGUNAR \& PALEOPONTAL A planície de Campos Verdes é limitada a SW pela margem nordeste da laguna Santa Marta, incluindo antigos fundos lagunares hoje emersos ou vegetados. Trata-se de terreno plano, baixo $(<1 \mathrm{~m})$ e portanto intermitentemente alagado por influência de marés. Entre esta margem lagunar brejosa e o feixe de cordões, encontra-se terreno mais alto (altitude $2 \mathrm{~m}$ ) sem cordões aparentes. Com formato de faixa estreita (menos de $1 \mathrm{~km}$ ) e alongada (cerca de 4 $\mathrm{km}$ ), paralela à margem lagunar, este terreno pode corresponder a um antigo pontal arenoso. Seu detalhamento no campo (Fig. 7A) permitiu observar que sua passagem para os depósitos lagunares brejosos materializa-se como pelo menos duas sucessivas quebras decimétricas de relevo, com forma semelhante a degraus.

Depósitos arqueológicos $\mathrm{O}$ sambaqui Carniça I (datado em 3370 150 anos A.P. por DeBlasis et al. 2007) situa-se sobre o paleopontal, na porção sudoeste, e é cortado pela estrada não pavimentada que atravessa a planície. Até o início da década de 1980, o calcário conchífero desse sambaqui foi intensamente lavrado por empresa de mineração, motivo pelo qual atualmente é possível reconhecer apenas alguns contornos de sua morfologia original (Fig. 7B). Atualmente, sua altura máxima é de $20 \mathrm{~m}$.

O sambaqui Carniça III, a leste da estrada, é um montículo arenoso de aproximadamente $3,5 \mathrm{~m}$ de altura (Fig. 7C), coberto por capa decimétrica preta de areia argilosa com matéria orgânica coloidal, contendo conchas de Anomalocardia brasiliana (Fig. 7D). Não foram observadas estruturas internas, nas areias dos sambaquis (Fig. 7D), que pudessem ser atribuídas à deposição pelo vento. Além disso, a forma e a altura dos sambaquis são incompatíveis com as dos depósitos eólicos existentes na região. Isso permite concluir que a existência de sambaquis de matriz arenosa, característicos da área de Campos Verdes, mas presente também sobre a barreira holocênica nos chamados sambaquis de Encantadas (Rohr 1969), deve-se à utilização deliberada de areia como material construtivo pelas populações sambaquieiras.

Sub-superfície As seções obtidas com o GPR podem ser divididas em duas fatias ou radar-fácies (Fig. 8). A radar-fácies superior, com aproximadamente $2 \mathrm{~m}$ de espessura, apresenta refletores mais marcados, paralelos e regulares que a inferior. Com base nos dados de trincheiras, esta fatia superior corresponde a depósitos arenosos insaturados em água, acima do nível freático, este bem registrado por refletor contínuo, quase hori- 

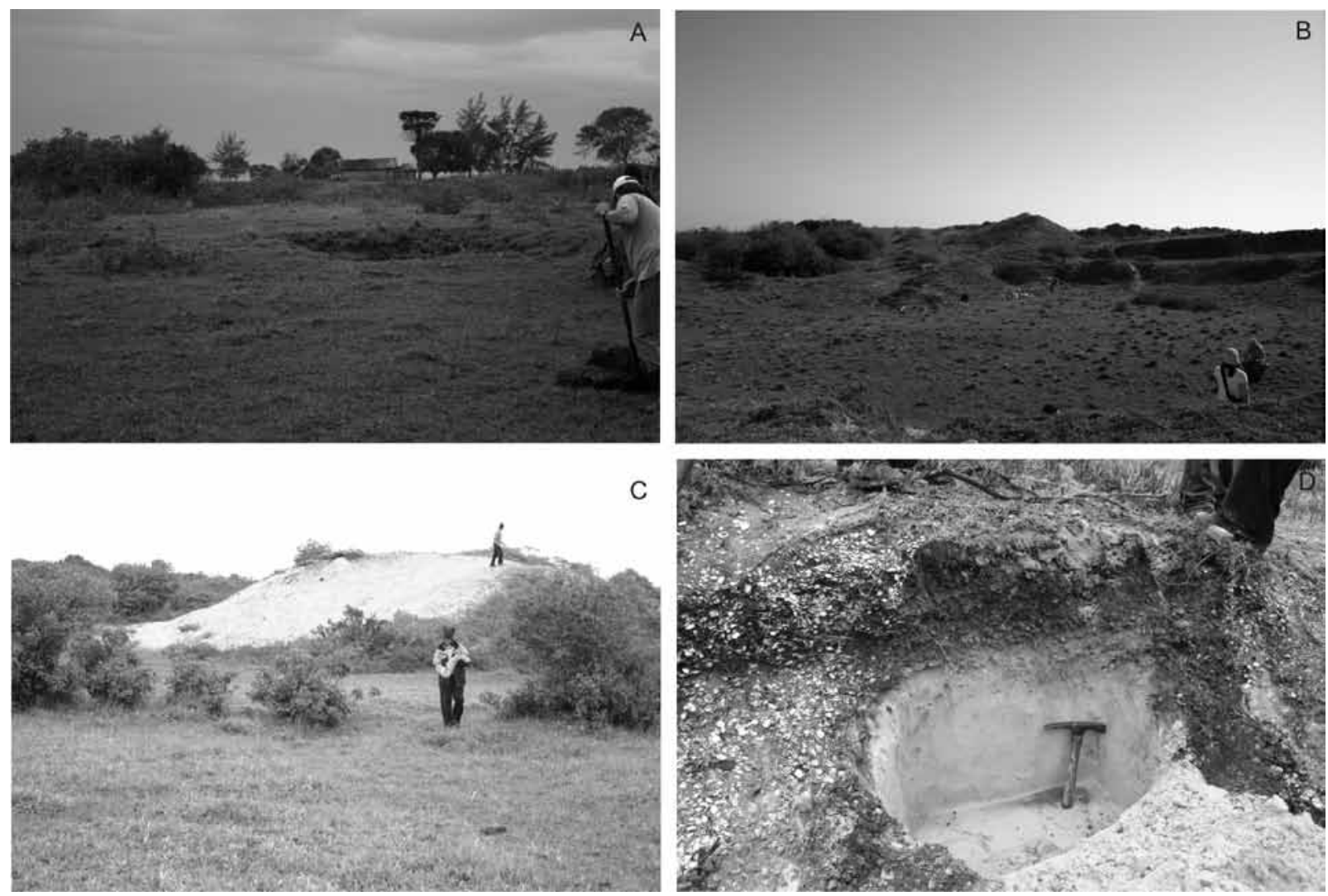

Figura 7 - Aspecto da porção sudoeste da planície. A) Transição entre margem lagunar e paleopontal, no ponto CV.14. B) Morfologia remanescente do sambaqui Carniça I. Na parte direita da fotografia, observam-se antigas frentes de lavra de calcário conchifero. C) Sambaqui Carniça III visto de norte, evidenciando-se sua constituição dominantemente arenosa. D) Detalhe da capa de argila arenosa com conchas de moluscos, repousando diretamente sobre a areia que constitui maior parte do sambaqui Carniça III.

zontal. O contraste de reflexão na altura do nível de água deve-se ao elevado valor de constante dielétrica dos sedimentos saturados em água, se comparados aos depósitos secos ou insaturados.

$\mathrm{Na}$ fácies inferior dos radargramas, os refletores apresentam mergulho aparente para quadrantes de norte, nos trechos transversais aos cordões litorâneos (NE nas seções da Fig. 8A), mas tornam-se irregularmente ondulados, tendendo em escala mais ampla a subhorizontais, nos trechos onde o perfil é sub-paralelo aos cordões (Fig. 8B e 8C). A inversão de mergulho, a ângulos suaves, notada no meio da seção da figura $8 \mathrm{C}$, indica que a paleossuperfície deposicional, neste trecho, é ligeiramente convexa para cima (os radargramas apresentam exagero vertical de 20 vezes). Esta interpretação é reafirmada pela convexidade dos cordões rumo NE, em planta, no mesmo trecho. Os refletores desta radar-fácies são bem visíveis até a profundidade aproximada de $5 \mathrm{~m}$, mas a partir desta profundidade há atenuação de sinal possivelmente relacionada a presença de sedimentos mais argilosos.

O mergulho verdadeiro das clinoformas, para norte, indica crescimento progradacional da planície de cordões de Campos Verdes para esse quadrante. Partindo da premissa de que a progradação dos cordões ocorreu rumo à porção mais aberta da laguna, conclui-se que a circulação hidrodinâmica na época de desenvolvimento da planície seria mais franca junto à desembocadura da Entrada da Barra, a NE, que na região onde hoje se encontra a desembocadura do Camacho, a SW.

\section{Sedimentologia}

GRANULOMETRIA Com base na variação de atributos granulométricos em perfil transversal aos cordões (Fig. 9), pode-se inferir tendência para afinamento (aumento do diâmetro médio na escala phi), melhora de seleção (queda de desvio-padrão) e diminuição de assimetria para norte, tanto nas amostras de cordão (Fig. 9A), como nas de duna eólica (Fig. 9B). A variação combinada "mais fino, melhor selecionado e mais negativo" coincide com um dos padrões indicadores de transporte sedimentar, considerados seguros ou inequívocos por McLaren \& Bowles (1985). No presente caso, como se trata de tendência detectada transversalmente à sucessão de cordões, do mais antigo para o mais recente, a interpretação é de retrabalhamento sedimentar seletivo durante a progradação. Assim, a variação estudada refletiria o próprio crescimento da planície para norte. Para os coeficientes de determinação $\left(r^{2}\right)$ obtidos, o nível de significância resultou em 0,1 para o parâmetro diâmetro médio (duna) e 0,2 para o di- 


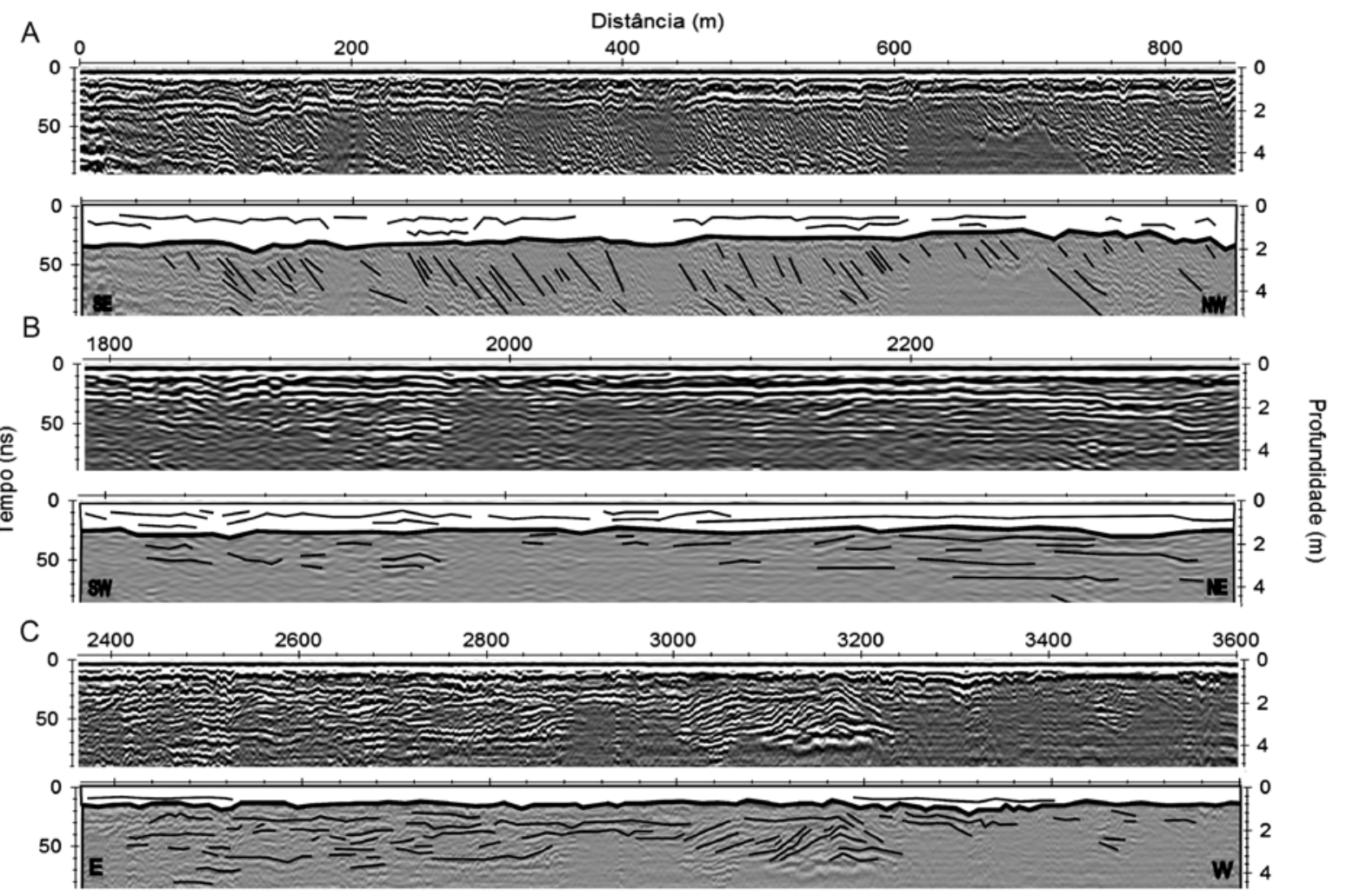

Figura 8 - Trechos das seções geofisicas (GPR) e seções interpretadas. A) Trecho inicial ( SE-NW), transversal aos feixes de cordões. B) Trecho médio ( $S W-N E$ ), sub-paralelo aos feixes de cordões. $C$ ) Trecho final $(E-W)$, paralelo aos feixes de cordões. $O$ nivel freático está destacado na interpretação pela linha preta mais espessa.

âmetro médio e desvio padrão (cordão), ou seja, a probabilidade de as correlações apresentadas nos gráficos serem inexistentes é de aproximadamente $10 \%$ e $20 \%$ respectivamente. Já o desvio padrão (dunas) e a assimetria (cordão e duna) apresentaram alta probabilidade de rejeição da hipótese nula (40\%). Sem considerar o dado de assimetria, não é possível relacionar essa tendência aos padrões indicadores de transporte (ou, neste caso, de retrabalhamento sedimentar por progradação) conforme McLaren \& Bowles (1985). Porém, é importante lembrar que o aumento de seleção relacionado a afinamento de granulometria é um indicador clássico de rumo de transporte e/ou retrabalhamento sedimentar (Evans, 1939).

Em perfil longitudinal (Fig. 9C), há tendência de engrossamento, melhora de seleção e assimetria mais positiva de $\mathrm{E}$ para $\mathrm{W}$, outro padrão indicador de transporte sedimentar segundo o método de McLaren \& Bowles (1985). Nesse caso, o método foi aplicado a uma mesma linha de tempo, como proposto originalmente pelos autores, e sugere transporte por corrente de deriva litorânea. Para os coeficientes de determinação $\left(\mathrm{r}^{2}\right)$ obtidos, o nível de significância resultou igual a 0,4 , para diâmetro médio e desvio padrão, e 0,05 , para assimetria.

A alta probabilidade de rejeição da hipótese nula verdadeira, para alguns parâmetros estatísticos indicadores desta suposta tendência de retrabalhamento e transporte, pode ser explicada pela relativa homogeneidade textural apresentada pelas areias da planície, bem como pelos pequenos intervalos de distância entre os pontos de amostragem (em alguns casos, menores que $400 \mathrm{~m}$ ). Este segundo aspecto é uma das críticas apresentadas ao método de McLaren \& Bowles (1985) por Gao \& Collins (1991), segundo a qual a ordem dos padrões de distribuição granulométrica pode ser destruída ou obliterada quando as amostragens apresentam pequenos intervalos de distância, sob gradiente baixo nos parâmetros granulométricos. Dessa maneira, o fato de o teste de significância rejeitar a hipótese de existência de rumo preferencial de transporte sedimentar não quer dizer necessariamente que este transporte preferencial não tenha existido no sistema deposicional (Gao \& Collins 1991). Outra maneira de testar esses padrões é utilizar o software GSTAST (Grain Size Trend Analysis with Significant Test), desenvolvido por Chang et al. (2001), para inferir rumo de retrabalhamento e transporte sedimentar. Apesar deste software ter sido elaborado para inferir transporte sedimentar em uma rede desenvolvida ao mesmo tempo, verificou-se eficácia quando aplicado para inferir retrabalhamento em perfil transversal a diferentes linhas de tempo. Os vetores aceitos indicaram transporte e/ou retrabalhamento, grosso modo, para N (Fig. 10).

MINERAIS PESADOS Na fração não magnética da classe granulométrica areia muito fina, foram encontrados os seguintes minerais transparentes não-micáceos, em ordem decrescente de abundância média: turmalina, 

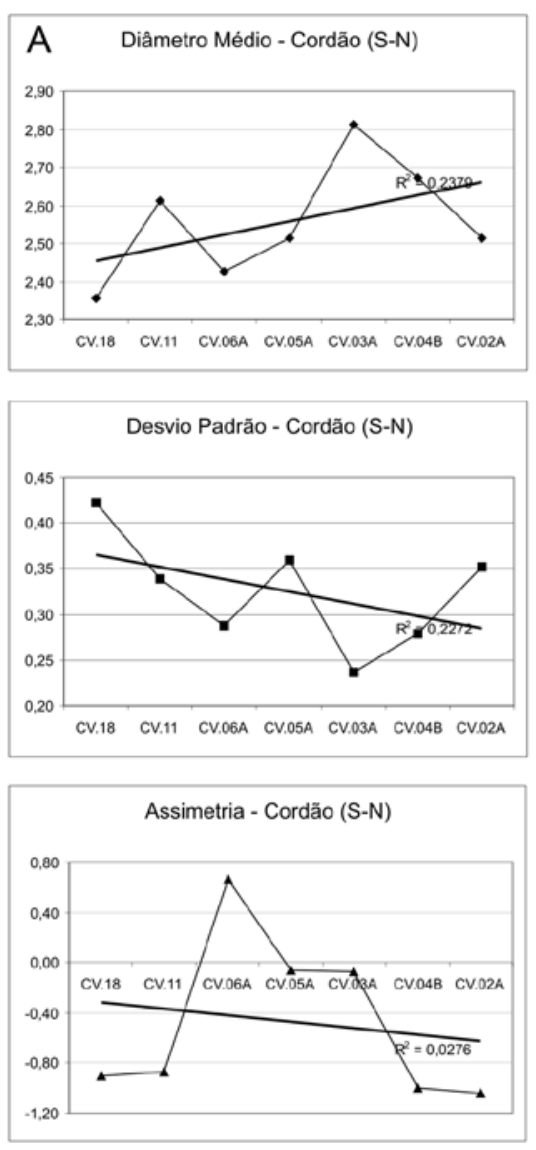
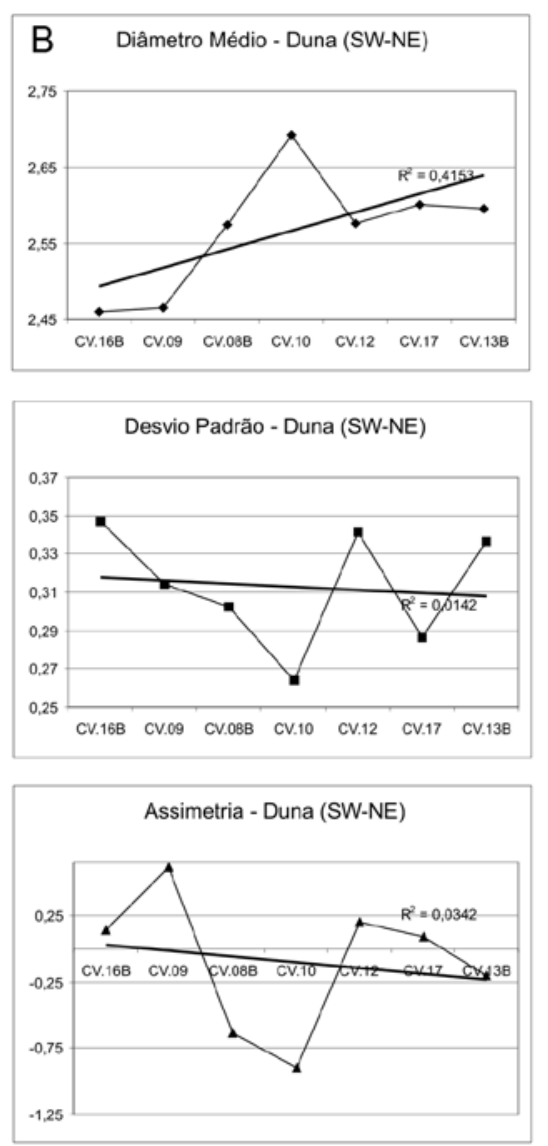
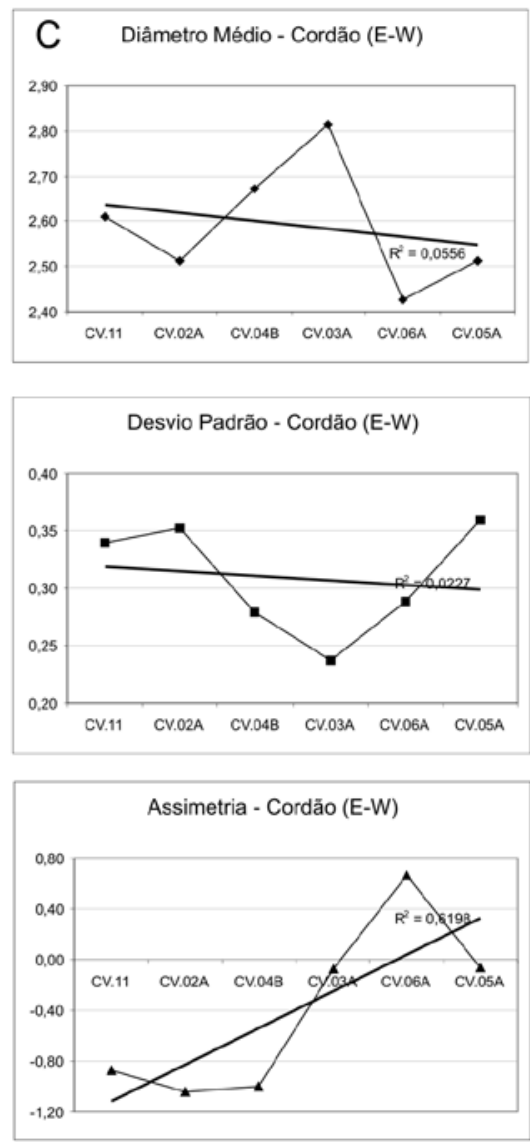

Figura 9 - Variação dos parâmetros estatísticos da distribuição granulométrica da fração areia. A) Para amostras de cordão em perfil transversal aos alinhamentos, de S para N. B) Para amostras de duna em perfil transversal aos alinhamentos, de SW para NE. C) Para amostras de cordão em perfil aproximadamente longitudinal à orientação predominante dos alinhamentos.

zircão, epídoto, hornblenda, estaurolita, "alterita" (sen$s u$ van Andel 1958), cianita, rutilo, sillimanita, granada, tremolita, clinopiroxênio (pigeonita/diopsídio), andaluzita, hiperstênio (opx) e glauconita. Observou-se também, em duas amostras, a presença de anatásio, possivelmente autígeno retrabalhado. A tabela 1 apresenta as freqüências de minerais pesados terrígenos encontrados nos sedimentos de Campos Verdes.

Zircão apresenta-se em grãos euédricos prismáticos a subédricos arredondados, por vezes com alto grau de esfericidade e freqüentemente com inclusões (Fig. 11A). Fraturamento interno observa-se eventualmente. Turmalina ocorre nas cores parda, verde e, em menor freqüência, azul, em formas tanto equidimensionais arredondadas como euédricas a subédricas prismáticas (Fig. 11B). Freqüentemente, exibe inclusões. Epídoto apresenta-se anguloso, com aspecto corroído (Fig. 11C) e relevo eventualmente alterado, ou em grãos equidimensionais bem arredondados, com relevo alto preservado. Hornblenda ocorre nas cores verde, verde amarronzado e, em alguns casos, pardo avermelhado (Fig. 11D). Dentre os minerais metamórficos estaurolita (Fig. 11E), cianita (Fig. 11F) e sillimanita (Fig. 11G), o primeiro é o mais abundante e ocorre em grãos subangulosos a subarredondados. Rutilo apresenta-se em cristais avermelhados, arredondados a subarredondados (Fig. $11 \mathrm{H})$.

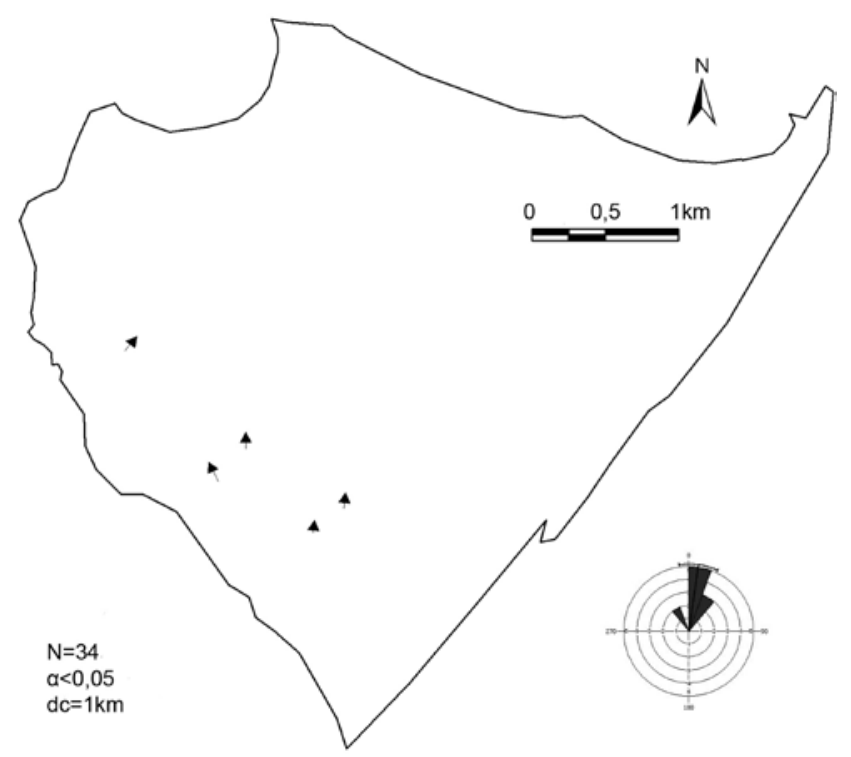

Figura 10 - Vetores de retrabalhamento e transporte sedimentar aceitos pelo programa GSTAST. As magnitudes dos vetores, indicativas da consistencia para cada possivel rumo de transporte, e representadas pelo tamanho da seta, correspondem a: 0,92; 1,12; 1,16; 1,31 e 1,51(valor adimensional). 
Tabela 1 - Freqüências percentuais médias dos minerais pesados terrigenos, turmalina (tur), zircão (zir), epídoto (epi), hornblenda (hbl), estaurolita (est), cianita (kya), rutilo (rut), sillimanita (sil), granada (grt), tremolita (tre), clinopiroxênio (pigeonita/diopsídio, cpx), andaluzita (and), hiperstênio (opx), glauconita (glc) e anatásio (ana), encontrados na fração areia muito fina dos sedimentos de Campos Verdes.

\begin{tabular}{c|c|c|c|c|c|c|c|c|c|c|c|c|c|c|c}
\hline & tur & zir & epi & hbl & est & kya & rut & sil & grt & tre & cpx & and & opx & glc & ana \\
\hline $\mathbf{2 1 - 5 0 \%}$ & $\mathrm{X}$ & & & & & & & & & & & & & & \\
\hline $\mathbf{6 - 2 0 \%}$ & & $\mathrm{X}$ & $\mathrm{X}$ & $\mathrm{X}$ & $\mathrm{X}$ & $\mathrm{X}$ & & & & & & & & & \\
\hline $\mathbf{2 - 5 \%}$ & & & & & & & $\mathrm{X}$ & & & & & & & & \\
\hline$<\mathbf{2 \%}$ & & & & & & & & $\mathrm{X}$ & $\mathrm{X}$ & $\mathrm{X}$ & $\mathrm{X}$ & $\mathrm{X}$ & $\mathrm{X}$ & $\mathrm{X}$ & $\mathrm{X}$ \\
\hline
\end{tabular}
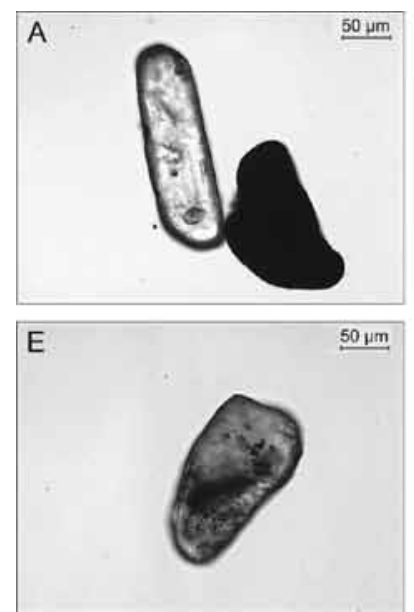
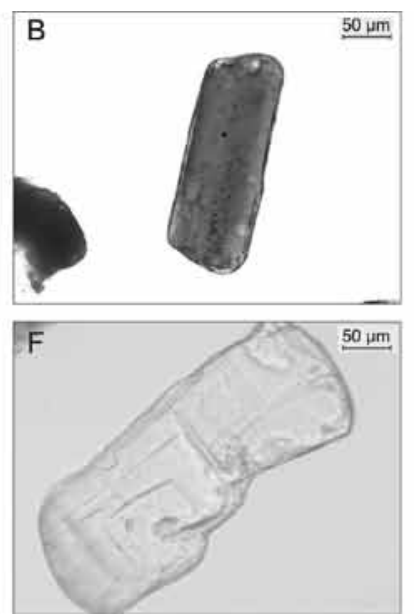
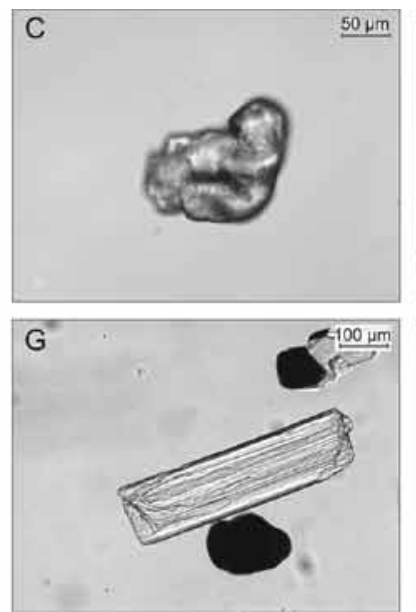
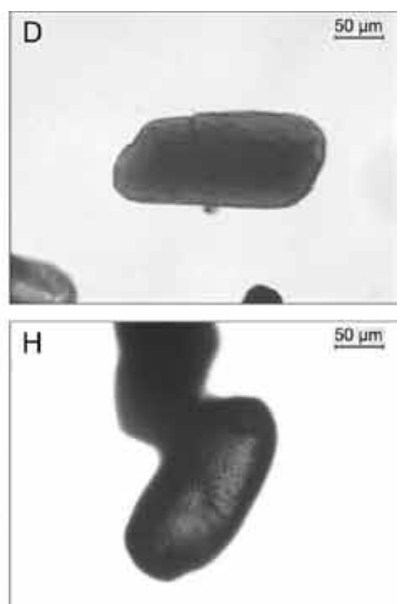

Figura 11 - Aspectos típicos de alguns minerais pesados observados ao microscópio petrográfico com polarizadores paralelos. A) Zircão prismático bi-terminado, subarredondado, com inclusões. B) Turmalina parda subédrica prismática, com inclusões alinhadas. C) Epídoto anédrico equidimensional, com aspecto corroído. D) Hornblenda alongada. E) Estaurolita subarredondada. F) Cianita prismática subarredondada. G) Sillimanita prismática subangulosa. H) Rutilo avermelhado, arredondado.

Ao exame da variação transversal e em área dos índices de maturidade mineralógica (Fig. 12A e 13A) para amostras de cordão e duna, ressalta-se a maior freqüência de componentes instavéis (iINS) em relação aos ultraestáveis (iZTR) no norte da planície e a tendência geral de queda de maturidade rumo $\mathrm{N}$ e NE. Este padrão de variação espacial da mineralogia pode ser explicado, isolada ou combinadamente, por pelo menos três hipóteses distintas. A primeira é a concentração progressiva, por seleção hidráulica durante o retrabalhamento progradacional, de minerais pesados relativamente menos densos, na sua maioria instáveis. A segunda hipótese explica a maior maturidade mineralógica dos sedimentos da parte sudoeste da planície com base em sua idade mais antiga: haja visto o crescimento gradual da planície de sul para norte, os depósitos situados mais ao sul teriam sofrido maior tempo de atuação da dissolução pós-deposicional, com eliminação preferencial de minerais instáveis. A terceira explicação está relacionada a uma particularidade da dinâmica costeira responsável pela formação da planície, segundo a qual haveria maior influência do aporte de sedimentos "novos", ricos em instáveis, no setor formado ao final da progradação (norte), através do aporte vazante da desembocadura da Entrada da Barra, ligado ao rio Tubarão.

Para testar a primeira hipótese, a de seleção hidráulica, foram construídos gráficos de variação e mapas de interpolação do índice turmalina-zircão (iTZ - Fig. 12B e 13B), dois minerais de mesma estabilidade (segundo Pettijohn 1957), mas de equivalentes hidráulicos muito diferentes. O resultado encontrado, aumento do iTZ rumo N, reforça a hipótese de controle hidráulico na variação espacial da mineralogia.

Para testar a segunda hipótese, de dissolução pós-deposicional, foram construídos gráficos de variação para amostras de cordão e duna e mapas de interpolação para amostras de cordão, do índice hornblenda-turmalina (iHT - Fig. 12C e 13C), dois minerais de equivalentes hidraúlicos semelhantes, porém de estabilidades químicas contrastantes (turmalina muito mais estável que hornblenda). O resultado encontrado, aumento para norte no iHT, é coerente com a hipótese de menor tempo de atuação da dissolução pós-deposicional, isto é, menor eliminação química de hornblenda, na porção norte da planície. Porém, a variação en- 

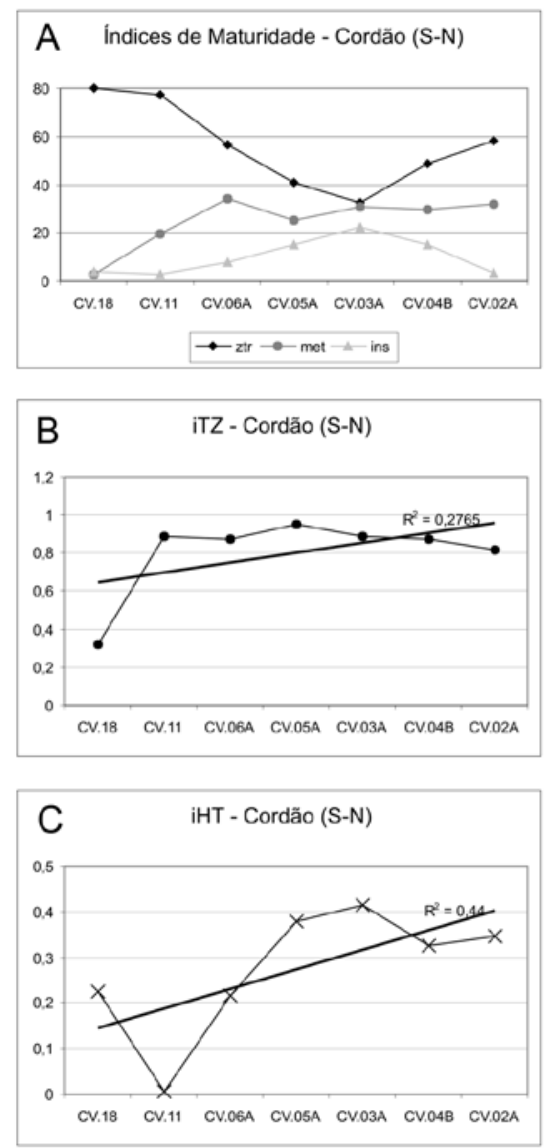
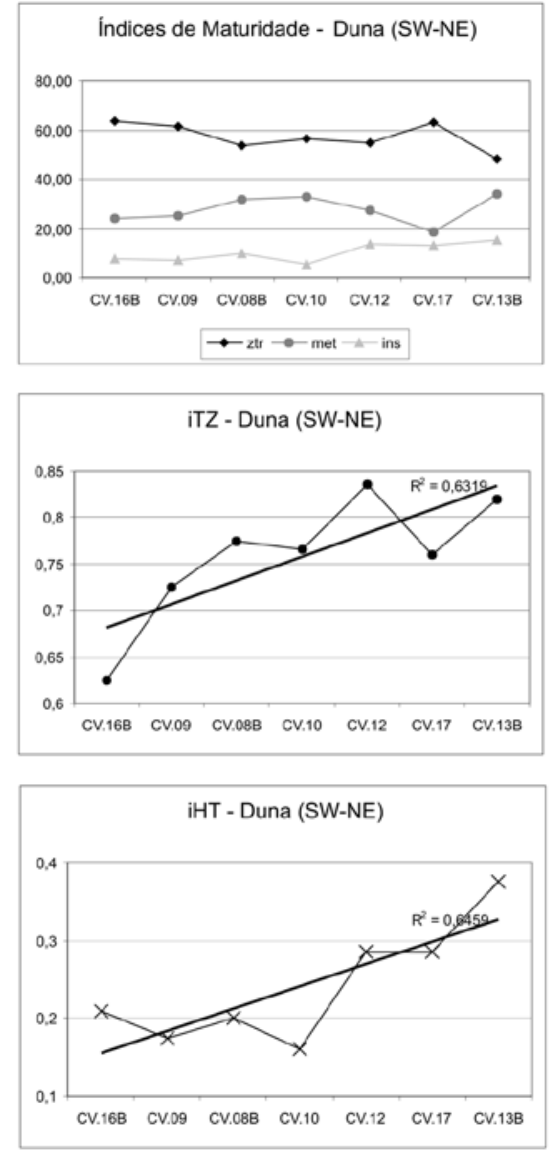
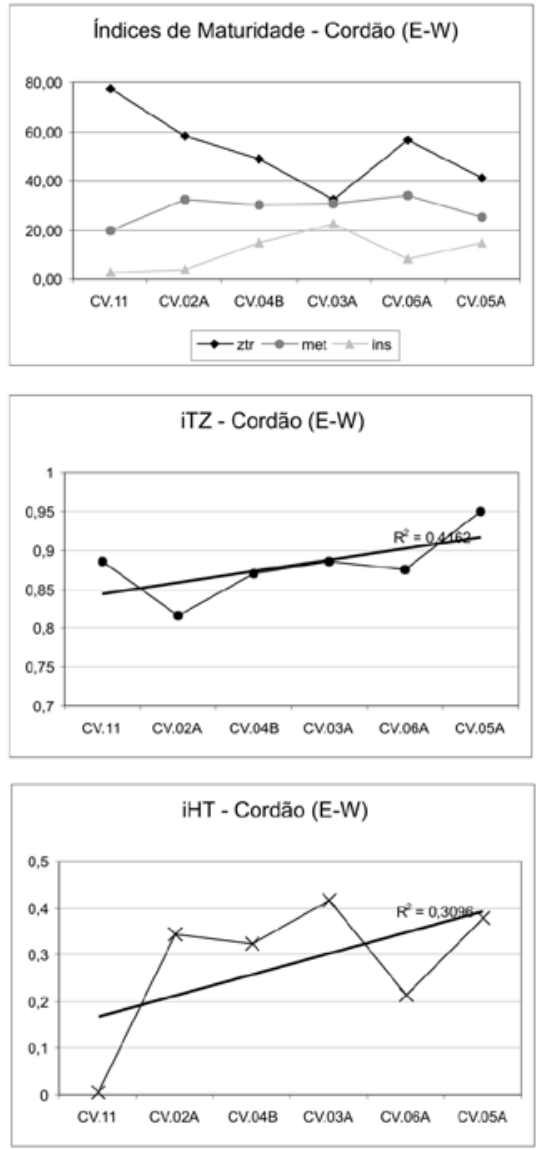

Figura 12 - Variação dos índices de minerais pesados da fração areia. A) Variação dos índices de maturidade ao longo dos perfis transversais para amostras de dunas e cordões, de S para Ne SW para NE, respectivamente, e variação em perfil longitudinal, de E para W para amostras de cordão. B) Variação do iTZ ao longo dos perfis transversais para amostras de dunas e cordões, de S para N e SW para NE, respectivamente, e variação em perfil longitudinal, de E para $W$ para amostras de cordão. C) Variação do iHT ao longo dos perfis transversais para amostras de dunas e cordões, de S para N e SW para NE, respectivamente, e variação em perfil longitudinal, de E para W para amostras de cordão..

contrada no iHT pode ao mesmo tempo ser usada como argumento a favor da terceira hipótese, a de influência crescente ao longo do tempo (para norte) da frente deltaica do rio Tubarão, desde que os sedimentos deste rio sejam de fato menos maturos e, assim, relativamente enriquecidos em hornblenda e empobrecidos em turmalina. Dados quantitativos inéditos obtidos por D.R. Nascimento, Jr., para a assembléia de minerais pesados transparentes não micáceos do delta do Tubarão, indicam, em comparação com a planície de Campos Verdes, concentrações médias mais altas de minerais pesados pouco estáveis, como cianita (17\%), estaurolita (17\%) e hornblenda (12\%), e concentração média mais baixa de turmalina (6\%). Desse modo, é possível, de fato, que a elevação no iHT para norte reflita um incremento na influência de sedimentos fornecidos pelo rio Tubarão, conforme evocado na terceira hipótese.

Como teste adicional para esta terceira hipótese, avaliou-se o comportamento espacial do índice rutilozircão (iRZ), dois minerais de densidade, forma e estabilidade semelhantes e cuja variação é, portanto, indicadora potencial de mudanças de proveniência sedimentar.
A variação encontrada neste índice em Campos Verdes (Fig. 13D), apesar de não linear, confirma a possibilidade de mudança de área fonte ao longo do tempo (de E e SE para $\mathrm{W}$ e NW), o que constitui reforço adicional para a hipótese de renovação ou incremento da influência do aporte deltaico sobre a planície de cordões.

Quanto à variação de atributos mineralógicos em perfil longitudinal ao cordão, nota-se aumento de iINS em detrimento do iZTR na porção oeste da planície (Fig. 12A), acompanhada de aumento de iTZ e iHT (Fig. $12 \mathrm{~B} \mathrm{e}$ 12C). Essa combinação de variações, admitida a hipótese de controle hidráulico sobre a distribuição dos sedimentos numa mesma linha de tempo, pode ser interpretada como reflexo de paleoderiva litorânea dirigida para W.

CONCLUSÕES As seções de GPR, com refletores mergulhando para NW, indicam crescimento progradacional da planície de Campos Verdes nesse rumo. Este dado reforça a hipótese, proposta em trabalhos prévios, de que a evolução sedimentar desta planície (Fig. 14) teve início a partir do ancoramento dos primeiros cordões no terreno mais alto (altitude de aproximadamente 


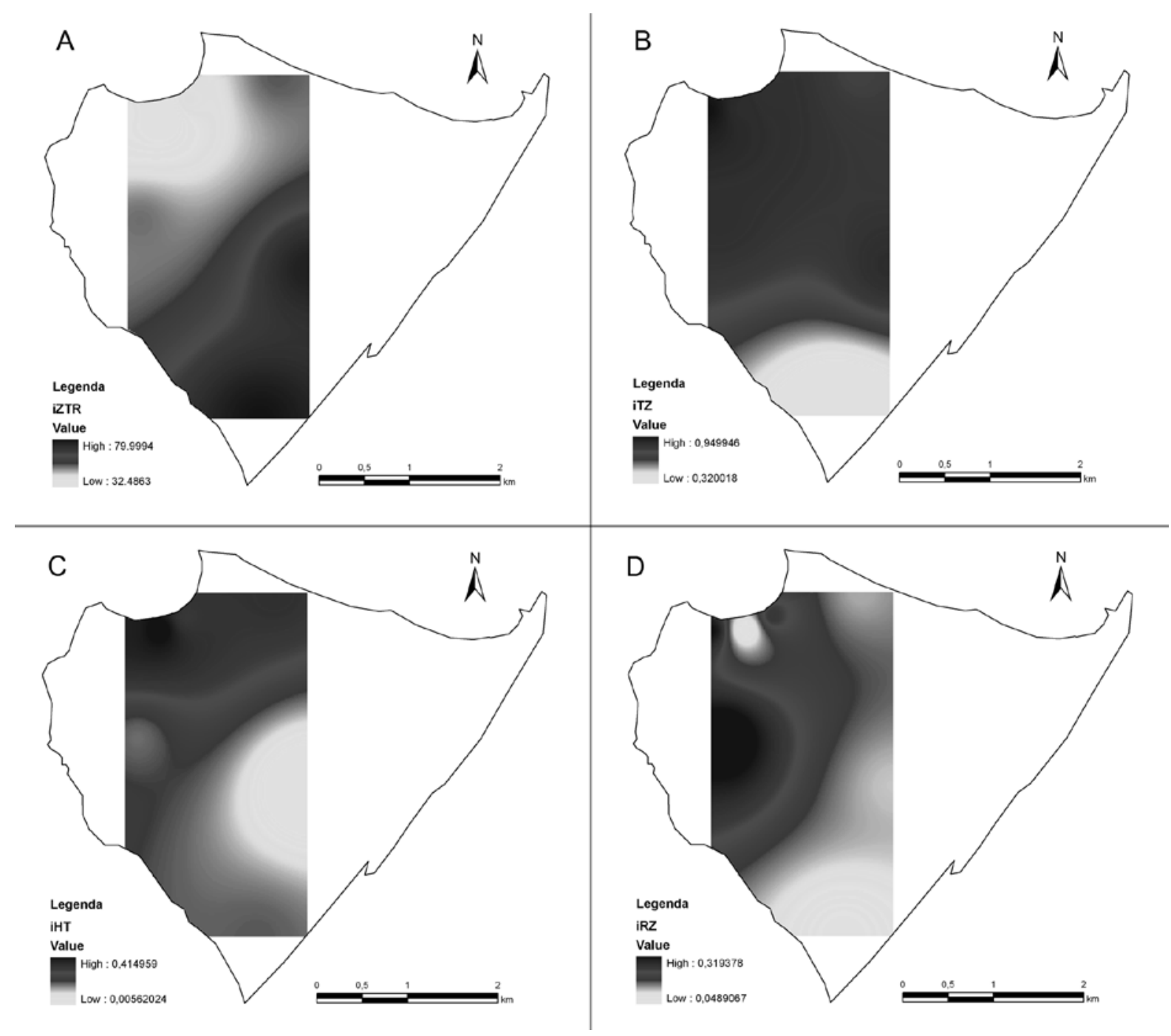

Figura 13 - Variação espacial de índices de minerais pesados da fração areia muito fina: A) iZTR.

B) iTZ. C) iHT. D) iRZ. Valores mais altos estão representados por tons de cinza mais escuros.

$2 \mathrm{~m}$ ) existente no seu limite sudoeste (margem nordeste da laguna Santa Marta). Pela disposição, estreita e alongada, e pela orientação, transversal ao eixo maior da paleolaguna, este terreno corresponde a um pontal de areia, formado segundo os modelos clássicos de circulação lagunar de Zenkovitch. Ele serviu como "armadilha" para o acúmulo progradacional de sedimentos formadores da planície de Campos Verdes.

Dez feixes de cordões litorâneos foram delimitados. Os dois primeiros, mais a sul e, portanto, mais antigos, possuem orientação média próxima de NE, ligeiramente oblíqua à direção da barreira. A partir do terceiro feixe, a orientação muda para E-W a NW, sub-perpendicular à barreira. Esta mudança de orientação pode ser indício de que os dois primeiros feixes formaram-se quando a feição em pontal ainda não se encontrava totalmente desenvolvida. É justamente no trecho desta feição mais próximo aos dois feixes mais antigos que se situam os sambaquis de Carniça. Em vista desta localização, estes sambaquis podem, em tese, apresentar idades mais antigas que a planície de cordões, correlatas à época imediatamente posterior à for- mação da barreira, por volta do máximo transgressivo (cuja idade, com base em dados regionais de variação de NRM, de Angulo et al. 1999, 2006, é igual ou maior que cerca de 5400 anos AP cal).

O modelo de crescimento da planície de Campos Verdes é corroborado pelas análises granulométricas, cuja tendência de variação transversal, para norte, coincide com um dos padrões considerados indicadores de rumo de transporte pelo "método de McLaren", o padrão "mais fino, melhor selecionado e mais negativo". Neste caso específico, a presença do padrão indicador de transporte é atribuída não ao fluxo sedimentar numa mesma linha de tempo, como na concepção original deste método, mas ao retrabalhamento gradual de sedimentos no decorrer da progradação, portanto cruzando as linhas de tempo aqui representadas pelos cordões. Já a variação longitudinal rumo W apresenta o padrão "mais grosso, melhor selecionado e mais positivo", também indicador de transporte sedimentar segundo mesmo método, o que sugere influência de correntes de deriva litorânea nesse rumo em cada linha de tempo. Permite supor que as frentes de onda mais atuantes vinham de quadrantes de leste, 


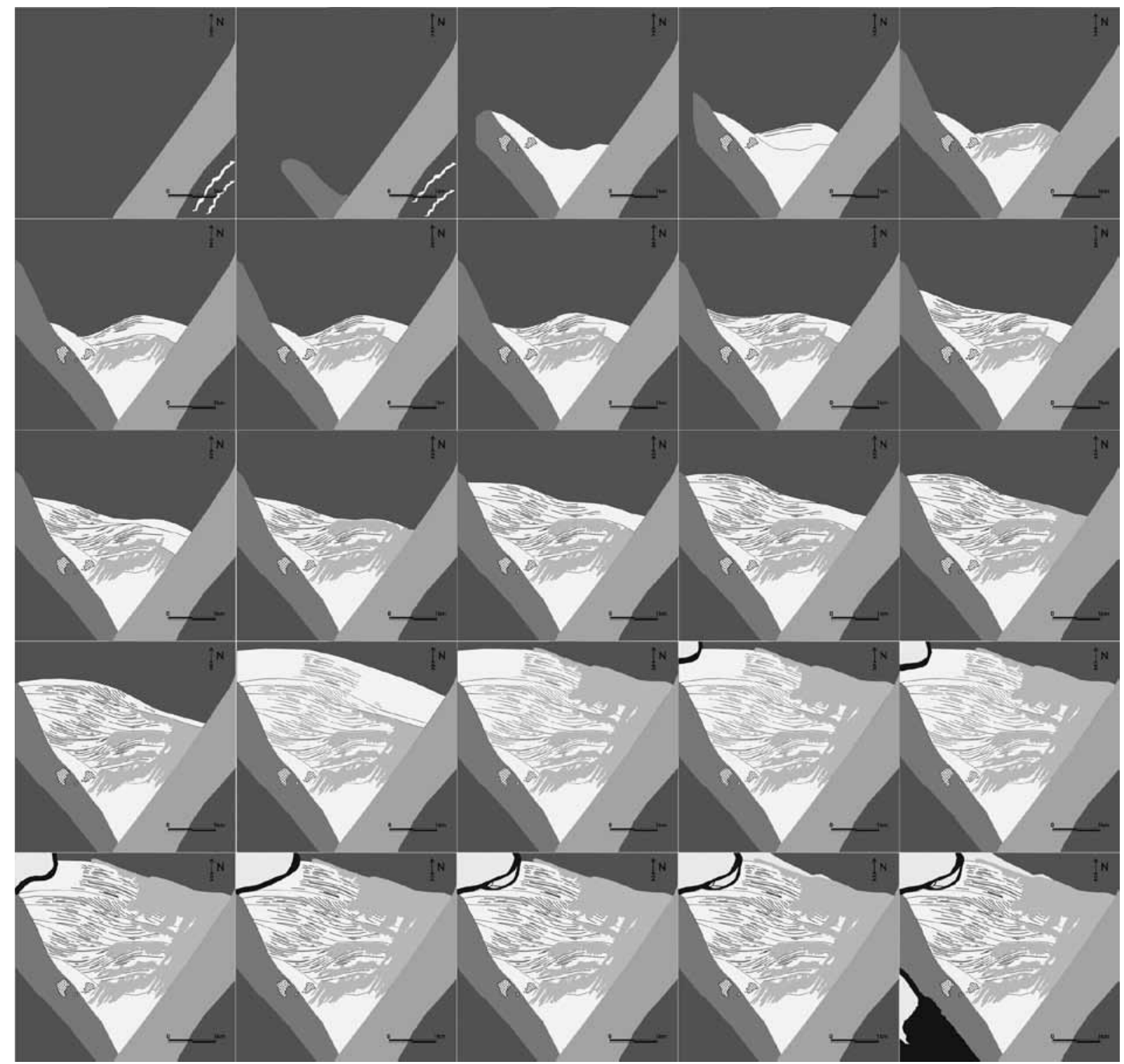

Figura 14 - Ilustração em etapas do modelo de evolução sedimentar da planície de Campos Verdes. Cada quadro corresponde a um momento do desenvolvimento da planície (ordenados da esquerda para a direita e de cima para baixo). As barras de escala correspondem a $1 \mathrm{~km}$.

através da desembocadura de Entrada da Barra.

Os resultados das análises de minerais pesados na fração areia muito fina evidenciam a maior freqüência de componentes instáveis em relação aos ultraestáveis no norte da planície e o padrão geral de queda de maturidade mineralógica e aumento do iTZ nesse rumo. A queda de maturidade mineralógica no setor formado ao final da progradação pode ser atribuída a três fatores: 1. Concentração progressiva, por seleção hidráulica, de minerais pesados menos densos (maioria instáveis), no transcorrer do retrabalhamento progradacional; 2 . Aumento do aporte de sedimentos "novos", ricos em minerais instáveis, em virtude da aproximação e maior influência da frente deltaica do rio Tubarão; 3. Menor tempo de atuação da dissolução pós-deposicional nos cordões mais novos, com maior preservação relativa de minerais instáveis.

Agradecimentos Os autores agradecem o apoio financeiro da FAPESP (Auxílio à Pesquisa Temático Proc. 2004/11038-0, Auxílio à Pesquisa Regular Proc. 2005/51034-6 e bolsa de Mestrado - Proc. 2008/507678) e a ajuda de Carlos Conforti Ferreira Guedes na construção de mapas de interpolação.

\section{Referências}

Angulo R.J., Giannini P.C.F., Kogut J.S., Prazeres Filho

H.J., Souza M.C. 1996. Variação das características sedimentológicas através de uma sucessão de cordões holocênicos, como função da idade deposicional, na 
ilha do Mel (PR). Bol. Paran. de Geoc., 44:77-86.

Angulo R.J., Giannini P.C.F., Suguio K., Pessenda L.C.R. 1999. Relative sea level changes during the last 5500 years in the Laguna-Imbituba region (Santa Catarina, Brazil), based on vermetid radiocarbon ages. Marine Geology, 159:323-339.

Angulo R.J., Lessa G.C., Souza M.C. 2006. A critical review of Mid-to Late Holocene sea-level fluctuations on the Eastern Brazilian coastline. Quat. Sci. Rev., 25:486-506.

Angulo R.J., Lessa G.C., Souza M.C. 2009. The Holocene Barrier Systems of Paranaguá and Northern Santa catarina Coasts, Southern Brazil. In: Dillenburg S.R. \& Hesp P. (eds.) Geology of the Brazilian coastal barriers. Lect. Notes in Earth Sciences, 107. Berlin, SpringerVerlag p. 135-176.

Blivi A., Anthony E.J., Oyéd L.M. 2002. Sand barrier development in the bight of Benin, West Africa. Ocean \& Coastal Management, 45:185-200.

Bristow C.S. \& Pucillo K. 2006. Quantifying rates of coastal progradation from sediment volume using GPR and OSL: the Holocene fill of Guichen Bay, south-east South Australia. Sedimentology, 53:769788.

Brook B.P., Ryan D., Piestch T., Olley J., Douglas G., Packet, R., Radke L., Flood P. 2008. Influence of climate fluctuations and changes in catchment land use on Late Holocene and modern beach-ridge sedimentation on a tropical macrotidal coast: Keppel Bay, Queensland, Australia. Marine Geology, 251: 195-208.

Chang H., Scrimshaw M.D., Lester J.N. 2001. A revised grain-size trend analysis program to define net sediment transport pathways. Comp. and Geosc., 27: 109-114.

Daniels D.J. 1996. Surface Penetrating Radar. London, The Institution of Electrical Engineers, $300 \mathrm{p}$.

Davis J.L. \& Annan A.P. 1989. Ground-penetrating radar for high resolution mapping of soil and rock stratigraphy. Geophys. Prosp., 37:531-551.

DeBlasis P., Kneip A., Scheel-Ybert R., Giannini P., Gaspar M.D. 2007. Sambaquis e Paisagem: Dinâmica Natural e Arqueologia Regional no Litoral Sul do Brasil. Arqueologia Sudamericanca/Arqueologia SulAmericana, 3(1) 29-61.

Dias G.T.M. \& Kjerfve B. 2009 .Barrier and Beach Ridge Systems of the Rio de Janeiro Coast. In: Dillenburg S.R. \& Hesp P. (eds.) Geology of the Brazilian coastal barriers. Lect. Notes in Earth Sciences, 107. Berlin, Springer-Verlag, p. 225-252.

Dillenburg S.R., Barboza E.G., Tomazelli L.J., AyupZouain R.N., Hesp P.A., Clerot L.C.P. 2009. The Holocene Coastal Barriers of Rio Grande do Sul. In: Dillenburg S.R. \& Hesp P. (eds). Geology of the Brazilian coastal barriers. Lect. Notes in Earth Sciences, 107. Berlin, Springer-Verlag, p. 53-91.

Dominguez J.M.L., Bittencourt A.C.S.P., Martin L. 1983. O papel da deriva litoranea de sedimentos arenosos na construcao das planicies costeiras associadas as desembocaduras dos rios Sao Francisco, Jequitinhonha, Doce e Paraiba do Sul. Rev. Brasil. Geocienc., 13:98105 .
Evans O.F. 1939. Sorting and transportation of material in swash and backwash. J. Sediment. Petrol., 9(1):2831.

Fitzgerald D.M., Cleary W.J., Buynevich I.V., Hein C.J., Klein A.H.F., Nils E.A., Angulo R. 2007. Strand plain evolution along the southern coast of Santa Catarina, Brazil. J Coastal Res., SI50:1-15

Galehouse J.S. 1971. Point counting. In: Carver R.E. (ed.) Procedures in Sedimentary Petrology. New York, Wiley-Interscience, p. 385-407.

Gao S. \& Collins M. 1991. A critique of the "McLaren Method" for defining sediment transport paths discussion. J. Sediment. Petrol., 61(1):143-146.

Gao S. \& Collins M. 1992. Net sediment transport patterns inferred from grain size trends, based upon definition of "transport vectors". Sediment. Geol. 81(1/2):4760.

Giannini P.C.F. 1993. Sistemas Deposicionais no Quaternário Costeiro entre Jaguaruna e Imbituba, $S C$. Tese de Doutoramento, Instituto de Geociências, Universidade de São Paulo, 2 v., 2 mapas, 439 p.

Giannini P.C.F. 2002. Complexo lagunar centro-sul catarinense - valioso patrimônio sedimentológico, arqueológico e histórico. In: Schobbenhaus C., Campos D.A., Queiroz E.T., Winge M., Berbert-Born M. (eds.) Sitios Geológicos e Paleontológicos do Brasil. Brasília, DNPM, 75, p.213-222.

Giannini P.C.F. 2007. Sistemas Deposicionais Eólicos no Quaternário Costeiro do Brasil. Tese de Livre Docência, Instituto de Geociências, Univ. de São Paulo, 205p.

Giannini P.C.F. \& Santos E.R. 1994. Padrões de variação espacial e temporal na morfologia de dunas de orla costeira no centro-sul catarinense. Bol. Paran. de Geoc., 42:73-96.

Giannini P.C.F., Sawakuchi A.O., Martinho C.T. 2001. A estratigrafia de seqüências na evolução das dunas costeiras de Santa Catarina, Sul do Brasil. In: Congr. do Quaternário dos Países de Língua Ibérica, Lisboa, Portugal, Actas, p. 117-120.

Giannini P.C.F., Guedes C.C.F., Angulo R.J., Assine M.L., Souza M.C., Mori E.K. 2003. Geometria de cordões litorâneos e espaço de acomodação sedimentar na ilha Comprida, litoral sul paulista: modelo baseado em aerofotointerpretação. In: Congresso da Associação Brasileira de Estudos do Quaternário (Abequa), 9, Recife, PE. Anais, CD-Rom.

Giannini P.C.F., Guedes C.C.F., Assine M.L., Angulo R.J., Souza M.C., Pessenda L.C.R., Tatumi S.H. 2003. Variação transversal e longitudinal de propriedades sedimentológicas nos cordões litorâneos da ilha Comprida, litoral sul paulista. In: Congresso da Associação Brasileira de Estudos do Quaternário (Abequa), 9, Recife, PE. Anais, CD-Rom.

Giannini P.C.F., DeBlasis P., Sawakuchi A.O., Amaral P.G.C. 2005. Processos e materiais geológicos e a construção de sambaquis no litoral sul de Santa Catarina. In: X Congr. da ABEQUA, 10, Guarapari - ES, Bol. de resumos expandidos, CD-Rom, p. 196.

Giannini P.C.F., Sawakuchi A.O., Martinho C.T., Tatumi S.H. 2007. Eolian depositional episodes controlled 
by Late Quaternary relative sea level changes on the Imbituba-Laguna coastal zone (southern Brazil). Marine Geology, 237:143-168.

Giannini P.C.F., Guedes C.C.F., Nascimento Jr. D.R., Tanaka A.P.B., Angulo R.J., Assine M.L., Souza M.C. 2009. Sedimentology and morphologic evolution of the Ilha Comprida Barrier System, southern São Paulo coast. In: Dillenburg S.R. \& Hesp P. (eds.) Geology of the Brazilian coastal barriers. Lect. Notes in Earth Sciences, 107. Berlin, Springer-Verlag, p. 177-224.

Guedes C.C.F. 2009. Evolução Sedimentar Quaternária da Ilha Comprida, Estado de São Paulo. Dissertação de Mestrado, Inst. De Geoc., Univ. São Paulo, 133 p.

Hesp P.A. 1984. The formation of sand 'beach-ridges' and foredunes. Search, 15:289-291.

Hesp P.A. 1999. The beach backshore and beyond. In: Short A.D. (ed.) Handbook of beach and shoreface morphodynamics, Chichester. NY, J. Wiley \& Sons, p. 145-170.

Hesp P.A, Dillenburg S.R., Barbosa E.G., Tomazelli L.J., Ayup-Zouain R.N., Esteves L.S., Gruber N.L.S., Toldo E.E., Tabajara L.L.C. de A., Clerot L.C.P. 2005. Beach ridges, foredunes and an examination of the Torres to Tramandaí barrier system, southern Brazil. Anais da Acad. Bras. de Ciências, 77(3):493-508.

Hesp P.A, Giannini P.C.F., Martinho C.T., Silva G.M., Asp N.E. 2009. The Holocene barrier systems of the Santa Catarina coast, southern Brazil. In: Dillenburg S.R. \& Hesp P. (eds.) Geology of the Brazilian coastal barriers. Lect. Notes in Earth Sciences, 107. Berlin, Springer-Verlag, p. 93-133.

Hubert J.F. 1962. A zircon-tourmaline-rutile maturity index and the interdependence of the composition of heavy mineral assemblages with the gross composition and texture of sandstones. J. Sediment. Petrol., 32(3):440450.

Hurt W.R. 1974. The interrelationships between the natural environment and four sambaquis, coast of Santa Catarina, Brazil. Indiana, Indiana Univ. Museum, 23 p. (Ocasional Papers and Monographs, 1).

Isla F.I. 1989. Holocene sea-level fluctuation in the Southern Hemisphere. Quatern. Sci. Rev., 8(4):359-368.

Isla F.I. \& Bujalesky G.G., 2000. Cannibalisation of Holocene gravel beach-ridge plains, northern Tierra del Fuego, Argentina. Marine Geology, 170:105-122.

Lessa G.C., Angulo R.J., Giannini P.C., Araújo A.D. 2000. Stratigraphy and Holocene evolution of a regressive barrier in south Brazil. Marine Geology, 187:87-108.

Mange M.A. \& Maurer H.F.W. 1992. Heavy Minerals in Colours. London, Chapman \& Hall, 147 p.

Martin L., Suguio K., Flexor J.M., Azevedo A.E.G., 1988. Mapa Geológico do Quaternário Costeiro dos Estados do Paraná e Santa Catarina. Brasília, DNPM, 40 p., 2 mapas. Série Geologia 28, Seção Geologia Básica 18.

McLaren P. \& Bowles D. 1985. The effects of sediment transport on grain-size distributions. J.Sediment. Petrol., 55(4):457-470.

Morton A.C. \& Hallsworth C.R. 1994. Identifying provenance-specific features of detrital heavy mineral assemblages in sandstones. Sediment. Geol., 90(3-4):241-256.

Morton A.C. \& Hallsworth C.R. 1999. Processes controlling the composition of heavy mineral assemblages in sandstones. Sediment. Geol., 124(1-4):3-29.

Otvos E.G. 2000. Beach ridges - definitions and significance. Geomorphology, 32:83-108.

Porsani J.L. 1999. Ground Penetrating Radar (GPR): Proposta Metodológica de Emprego em Estudos Geológico-Geotécnicos nas Regiões de Rio Claro e Descalvado - SP. Tese de Doutoramento, Instituto de Geoc. e Ciências Exatas, Campus de Rio Claro, Univ. Estadual Paulista - São Paulo, 145 p.

Pettijohn F.J. 1957. Sedimentary Rocks. 2nd edition, New York, Harper \& Row, 628 p.

Reitz J., Milford F.J., Christy R.W. 1982. Fundamentos de Teoria Eletromagnética. $3^{\mathrm{a}}$ ed., Rio de Janeiro, Editora Campus Ltda., 516 p.

Rohr J.A. 1969. Os sítios arqueológicos do município sulcatarinense de Jaguaruna. Pesquisas (Antropologia), 22:1-39.

Roy P.S., Cowell M.A., Ferland M.A., Thom B.G. 1994. Wave-dominated coasts. In: Carter R.W.G. \& Woodroffe C.D. (eds.) Coastal Evolution - Late Quaternary Shoreline Morphodynamics, 539 p.

Sawakuchi A.O., Kalchgruber R., Giannini P.C.F., Nascimento Jr. D.R., Guedes C.C.F., Umisedo N.K. 2008. The development of blowouts and foredunes in the Ilha Comprida barrier (Southeastern Brazil): the influence of Late Holocene climate changes on coastal sedimentation. Quaternary Science Reviews, 27:2076-2090.

Suguio K., Martin L., Bittencourt A.C.S.P., Dominguez J.M.L., Flexor J.M., de Azevedo A.E.G. 1985. Flutuações do nível relativo do mar durante o Quaternário superior ao longo do litoral brasileiro e suas implicações na sedimentação costeira. Rev. Brasil. de Geoc., 15:273286.

Tanaka A.P.B., Giannini P.C.F., Sawakuchi A.O. 2008. Rumo de crescimento progradacional da planície de cordões litorâneos de Campos Verdes (Laguna, SC). In: SBG, Congresso Brasileiro de Geologia, 44, Curitiba, Anais, p.969.

Tomazelli L.J. \& Villwock J.A. 2005. Mapeamento geológico de planícies costeiras: o exemplo da costa do Rio Grande do Sul. Gravel, 3:109-115.

Van Andel T.H. 1958. Discussion: a defense of the term alterite. Journ. of Sedim. Petrology, 28:234-235.

Woodroffe C.D., Curtis R.J., McLean R.F. 1983. Development of a Chenier Plain, Firth of Thames, New Zealand. Marine Geology 53:1-22.

Zenkovith V.P. 1971. Processes of Coastal Development. Edinburgh-London, Oliver \& Boyd, 738 p.

Manuscrito ID 13381

Submetido em 03 de fevereiro de 2008 Aceito em 17 de dezembro de 2009 